\title{
Gut Microbiota and Health: Understanding the Role of Diet
}

\author{
Reem Moath Alasmar ${ }^{1,2}$, Kavitha Varadharajan ${ }^{1 *}$, \\ Muralitharan Shanmugakonar ${ }^{1}$, Hamda A. Al-Naemi ${ }^{1,2}$ \\ ${ }^{1}$ Laboratory Animal Research Centre, Qatar University, Doha, Qatar \\ ${ }^{2}$ Department of Biological and Environmental Science, Qatar University, Doha, Qatar \\ Email: *kavithasajani@qu.edu.qa
}

How to cite this paper: Alasmar, R.M. Varadharajan, K., Shanmugakonar, M. and Al-Naemi, H.A. (2019) Gut Microbiota and Health: Understanding the Role of Diet. Food and Nutrition Sciences, 10, 1344-1373. https://doi.org/10.4236/fns.2019.1011097

Received: October 21, 2019

Accepted: November 24, 2019

Published: November 27, 2019

Copyright $\odot 2019$ by author(s) and Scientific Research Publishing Inc. This work is licensed under the Creative Commons Attribution International License (CC BY 4.0).

http://creativecommons.org/licenses/by/4.0/ (c) (i) Open Access

\begin{abstract}
Microbiome now is considered as an organ within our system to regulate metabolism, cellular immune response and eventually maintain the health. Gut microbiota has been studied extensively in the recent past due to the possibility of high-resolution analysis by next-generation sequencing technology. As the gut microbiota, is essential for the host development and physiological function, a gut microbial community dominated by Firmicutes and Bacteroidetes and their relative abundance and dysbiosis influences obese conditions and various disease progression. The microbiota dysbiosis in the gut contributed mainly by diet as a carbon economy of the colon apart from genetic and environmental variations. Postgenomic era reveals the paradigm of the gut-brain axis and association of gut microbial metabolites such as short chain fatty acids (SCFA) and disease progression of inflammatory bowel disorder (IBD) and colon cancer. In addition, the landscape of gut microbiome is influenced by other factors such as pregnancy, smoking, alcohol consumption and stress. The functional consequence of gut microbial dysbiosis towards disease progression and understanding their mechanism in terms of the immune response through studies on rodent animal models also are discussed in this review.
\end{abstract}

\section{Keywords}

Gut Microbiota, Dysbiosis, Lipopolysaccharides (LPS), Short Chain Fatty Acids (SCFA), Obesity, Diet

\section{Introduction}

Since the last decade interest on microbial community harboring gut region 
gained attention due to their importance and contribution to health and disease. Gut region is the dwelling place for more than trillion of microbes and comprises of enormous microbial community. Due to the great interest and importance of gut microbiota study, exploration of gut microbes fascinates the research community to understand their structure and function in the gut environment. As most of these microbes are not suitable for culturing in the laboratory condition, understanding and characterizing gut microbiota poses a challenge to the research community. Advent of metagenomics analysis using next generation sequencing technology made it possible to study them at their genome level hence the landscape of gut microbiome explored extensively at phyla and genera level.

Subsequently, many research reports explain microbiota's contribution and association with various disease conditions. Contribution of gut microbiome to metabolic disorders focused more on diabetes and obesity as diet plays a major role in stabilizing and sustaining a set of microbial population and the change in the diet influences population equilibrium in the gut, which eventually leads to gut microbial dysbiosis. Although the gut is sterile before birth but colonization of microbes in the gut starts during the first year after birth. Moreover, the stabilization of the gut microbiota depends on mode of delivery and breast-feeding, which plays an important role in maintaining a stable microbial community in the gut [1]. However, factors such as age, diet consumption, environmental factors and antibiotic treatments also play an important role in altering microbiota diversity in the gut.

Obesity is one of the major global health issues and it is linked to multiple diseases such as hypertension, type 2 diabetes mellitus, non-alcoholic fatty liver and cardiovascular disorders. Obesity is continuously increasing and affecting more than 107.7 million children and more than 603.7 million adults around the world. Especially in the developed countries, prevalence of obesity is steadily increasing and has been reported that the major cause of more than $60 \%$ of deaths is due to increased body mass. As the estimate says if this trend of obesity prevalence persists, more than $18 \%$ of men and $21 \%$ of women worldwide will be affected by 2025 [2].

Positive energy balance proved to be the fulcrum of this metabolic syndrome, when more energy consumed than expended, and uncontrolled consumption of food for longer period leads to fat deposition in adipocytes and easy weight gain. Additional contributing factors such as basal metabolic rate, genetic and environmental components play a role in the pathophysiology of this disease [3]. As far as the environmental factors concerned, eating habits and physical activity are the two main components which impose a major impact on the pathophysiology of obesity. Moreover, recent reports reveal the association and causative role played by gut bacteria in the manifestation of obese condition.

As per the human microbiome study by National Institute of Health, more than 70 bacterial phyla recorded in the gut region dominating with Bacteroidetes, Firmicutes, Actinobacteria and Proteobacteria. However, the gut microbiota 
abundance and activity of Bacteroidetes and Firmicutes were studied extensively due to their association with diet-induced obesity. Ley et al. [4] reported that bacterial richness is associated with Body Mass Index (BMI), obesity, dyslipidemia and insulin resistance. Clarke et al. [5] and Mozes et al. [6] reported the altered abundance of Bacteroidetes and Firmicutes due to high fat diet consumption. The role of gut microbiota in influencing the host metabolism involves range of mechanisms of which generating energetic substrate by fermentation is well explained, this process generates short chain fatty acids, acetate, butyrate and propionate [7] [8]. Most of them especially the acetate and propionate are involved in cholesterol and lipid synthesis; hence, the acetate/propionate ratio is critical in regulating cholesterol metabolism [7] [9]. Gut microbiota has influence on homeostasis of the intestinal epithelium and enhances the development of immune system followed by protection against pathogens [3].

The recent research emphasis on the gut microbiota gained importance from various findings, one such example is diet-induced obesity. The change in the microbiota due to the diet composition influences the metabolic function of host as well as microbes in the gut [10] [11]; change in energy metabolism and immune response [12]. Moreover, most of the recent findings pointing towards the fact that diet influence the intestinal microbiota dysbiosis, which leads to health illness such as infections, obesity, allergies, inflammatory bowel disorders etc. [13].

In this review, we explore the current findings related to contribution of microbiota in host metabolism, their interaction with cellular absorption of nutrients and as well as their impact on host immune response. It is also proven that the contribution of gut microbial population towards host health is facilitated by generating metabolites and acting as an intestinal barrier to control the absorption of molecules. Impact of environmental and life style factors on the microbiota discussed in detail.

Microbial ecosystem in gut region: Human body harbors more than $10^{14}$ microbes in the gut, the diversity of microbial population and their density increases from stomach to colon [14]. The gut microbiota is a diverse ecosystem consists of bacteria, archea, fungi and virus including bacteriophages [15]. Human and rodent's gut microbial communities are very similar at classification level and the most dominant microbial communities are Firmicutes and Bacteroidetes [3]. Other communities can be found in low proportion, such as Proteobacteria, Acinobacteria, Verrucomicrobia, Cyanobacteria, Fusobacteria and most of them are uncultivatable. Furthermore, gut microbial community differs across different anatomical sites, such as less phylogenetic diversity found in the small intestine than in the large intestine (Figure 1). Gut microbiota provides an ecosystem which mutually beneficial to them and to the host to support nutrition, regulating metabolism supporting immune response and body mass [16] [17]. Gut microbiota harbors some main ecosystem amenities such as provisioning of metabolites, regulating metabolism and supporting immune response. 


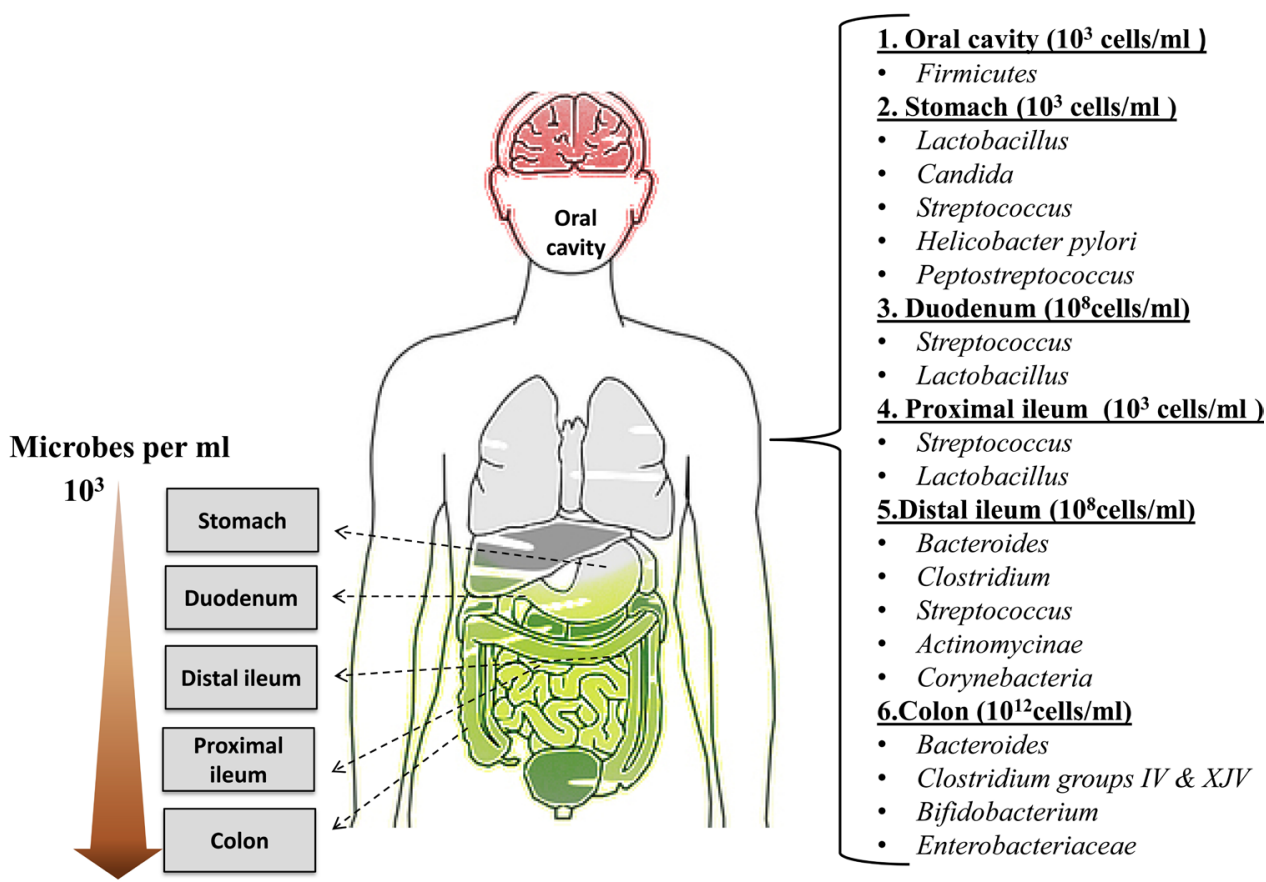
$10^{12}$

Figure Courtesy: (https://mybiohack.com)

Figure 1. Explains the microbial population in gut region.

Factors affecting the gut microbial diversity: Gastrointestinal tract is persistently in contact with diverse and dynamic microbial community; intestinal cells sense and react appropriately to signaling molecules produced by the gut microbiota. Intestinal barrier as a complex and natural containment system for the host involves in physical and immunological defense functions that control the entry of the pathogen into the system [18]. Moreover, several gut barrier components such as enterocytes in the tight junction [19], mucus layer [20], antimicrobial peptides [21], gut associated lymphoid tissues [22] play a major role in the gut homeostasis. Instability in the gut barrier components stimulates various metabolic and immunological signaling pathways; it is also proven that shift in normal gut microbial homeostasis might disturb the routine function of the barrier components. Apart from diet, gut microbiota extremely influenced by various factors (Figure 2) and respond swiftly when the system is altered; it is reported that majority of the changes probably results from the amalgamation of genetic and the environmental factors. Falony et al. [23] reported that sixty-nine covariates of systems were associated with the changes in the gut microbiota community. Crosstalk between these factors significantly influences the alteration of gut microbiota. Apart from the regulatory signaling pathways, gut to brain and brain to liver and or adipose tissues networking again coordinating all the vital metabolic pathways to control the various factors that lead to beneficial or adverse effects on the system. However, the mechanism behind the alteration of the gut microbial community and the contribution of various pathways to change the microbiota in the gut are not fully understood and well defined yet. The following sections will discuss in detail about some essential factors that 


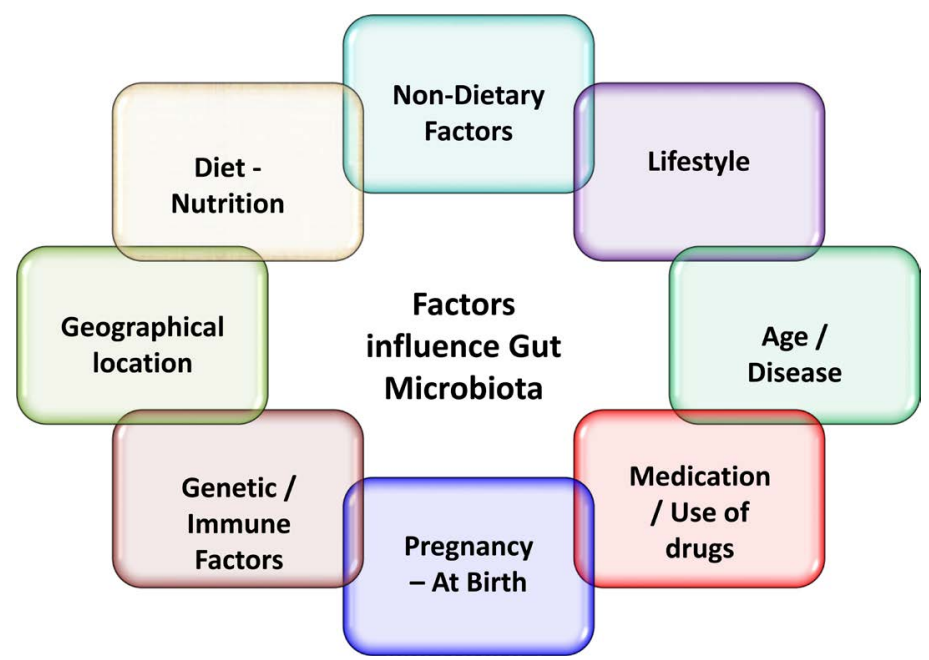

Figure 2. Describes various factors involved in the alteration of gut microbiota.

influences the gut microbiota.

\subsection{Pregnancy and at Birth}

Primarily an infant acquires microbiota from maternal microbiome through various sources. In fact, development and the composition of microbiota start from the time the mother get pregnant. Lamont et al. [24] reported that the microbiota composition differs between the pregnant and non-pregnant individuals. During pregnancy, physiological and immunological changes shift the composition of maternal gut microbiome and these alterations can have the impact on the metabolic and immunological profile of the infant [25] [26]. Recently, Aagaard et al. [27] reported that the placental microbiota is inter connected with preterm birth and they are abundant and prominent in the placenta. The placenta dominated by unique set of microbes and they are non-pathogenic commensals from the phyla Firmicutes, Bacteroidetes, Proteobacteria, Fusobacteria and Tenericutes. Collado et al. [28] studied gut microbial colonization in prenatal and neonatal in 15 mother-infant pairs and prenatal results revealed that the placenta, amniotic fluid and meconium contain typical microbial community with less population and low diversity similar to maternal microbial population. Studies on neonatal samples showed that the infant gut microbiota resembles the population in the colostrum. Jimenez et al. [29] observed microbial colonization in umbilical cord, amniotic fluid and in meconium of the infants and reported that the microbial isolates such as Enterococcus faecium, Propionibacterium acnes, Staphylococcus epidermis and Streptococcus sanguinis were observed from the umbilical cord samples.

In addition, the gut microbial population is diverse in newborns delivered by vaginal delivery compared to the children delivered through cesarean section. At the time of birth, newborns delivered by normal vaginal delivery exposed to the maternal microbiota that influences the infant's gut microbiota and stimulates the immune system [30]. Infant feeding is also a key factor for the development 
of gut microbiota in newborn and transfer of breast milk from mother to infant influences infant gut microbial growth and development. The maternal microbiota in the breast milk and the skin are the first microbes enter into the infant's body and this might play a major role in initiating the primary immune response to maintain the good health [31] [32]. However, very few reports about the microbial population in the amniotic fluid and the meconium are found and this warrant a thorough and extended study [33]. Altogether, the maternal lifestyle and microbiome composition is the primary source responsible for the early growth and development of the infant health system and this could change later in their life. Plethora of research findings supports the role of microbiota in the development of infant microbiome and health; however, still it is a matter of debate whether the gut microbiota develops before or after the birth of an infant. To understand these phenomena, microbiome studies using animal models are mandatory to get conclusive information about the development of gut microbiome in infancy [34].

\subsection{Genetic and Immune System}

Host genetic variations and immune response along with gut microbiota are the main drivers in association with gut microbiome which influences the variation in metabolic phenotype. This has been proved that microbiome colonization starts even during the gestational period and regulates the immune system of the progeny. After birth, the infant system gets maternal microbial population; their colonization and growth in the mucosal tissue activate the immune and nonimmune system that develops into a mature immune system. This will eventually establish into various immune mechanism to maintain the hemostasis along with gut microbiota to tolerate several environmental exposures [35]. Most of the gut microbiome associated with the immune response contributes to metabolic disorders such as obesity and diabetes [4] [36]. The relationship between the host genetic variation and the diversity of microbial population is still not clear. Understanding the mechanism behind the relationship between the host and gut microbiome is essential to reduce the health risk and this needs a detailed study of microbiota at various level. Again, genetic variation of the host that influences the immune response is one of the factors mainly contributing to the microbial diversity in the gut. However, studies on the association of host genetic variation and microbiome dysbiosis are limited. Variations in the genes associated with immune response, barrier defense and the physiological system, can lead to health disorder [37], which in turn shapes the gut microbiota. For example, genetic variation affecting the signaling events in inflammatory response or metabolic traits can later affect the microbial community significantly [38] [39]. Similar to quantifiable heritable trait such as Body Mass Index (BMI), some of the metabolites from host metabolism influence the gut microbiome composition and those metabolites can be treated as heritable trait [40]. 


\subsection{Dietary Habits/Nutrition}

After birth, diet or food habits of an individual play a vital role in the alteration of gut microbiota. Until now, the association between the diet and the gut microbiota has remained unclear. However, in the last decade different research groups explored that diet is one of the pre-eminence among all factors that affect the landscape of the gut microbiota. Different types of diet such as high carbohydrate, high fat, dietary fibers, western diet, pre/probiotics and vegetarian diet are mainly studied and shows a significant role in shifts/shaping the gut microbiome within 24 hours of food intake [41]. According to the type of diet-intake, mammals are classified into Herbivorous, Carnivorous and the omnivorous and they have their unique composition of gut microbiota [42]. Based on the type of diet, the genes involved in metabolic pathways also expressed accordingly to metabolize the specific diet components [43]. With all these diet variations, four phyla mainly Firmicutes, Bacteroidetes, Proteobacteria and Actinobacteria are dramatically altered in the system (Figure 3). Moreover, the composition, quantity, nature and nutritious balance of the dietary macronutrients such as carbohydrate, protein and lipids are the major driving force to shift the composition and the metabolism of gut microbiota.

Normal human gut comprises of $10^{14}$ commensal microbial community including bacteria, viruses, fungi and protozoa [44]. The diet after ingestion digested in stomach and pass through small intestine and the final undigested food reaches large intestine. Gut microbes resides in the large intestine greatly contribute to the host health through metabolic biosynthesis and signaling pathways. The undigested food fermented by the gut microbiota helps to generate the metabolic by-products that are the precursors to stimulate the bio-signaling

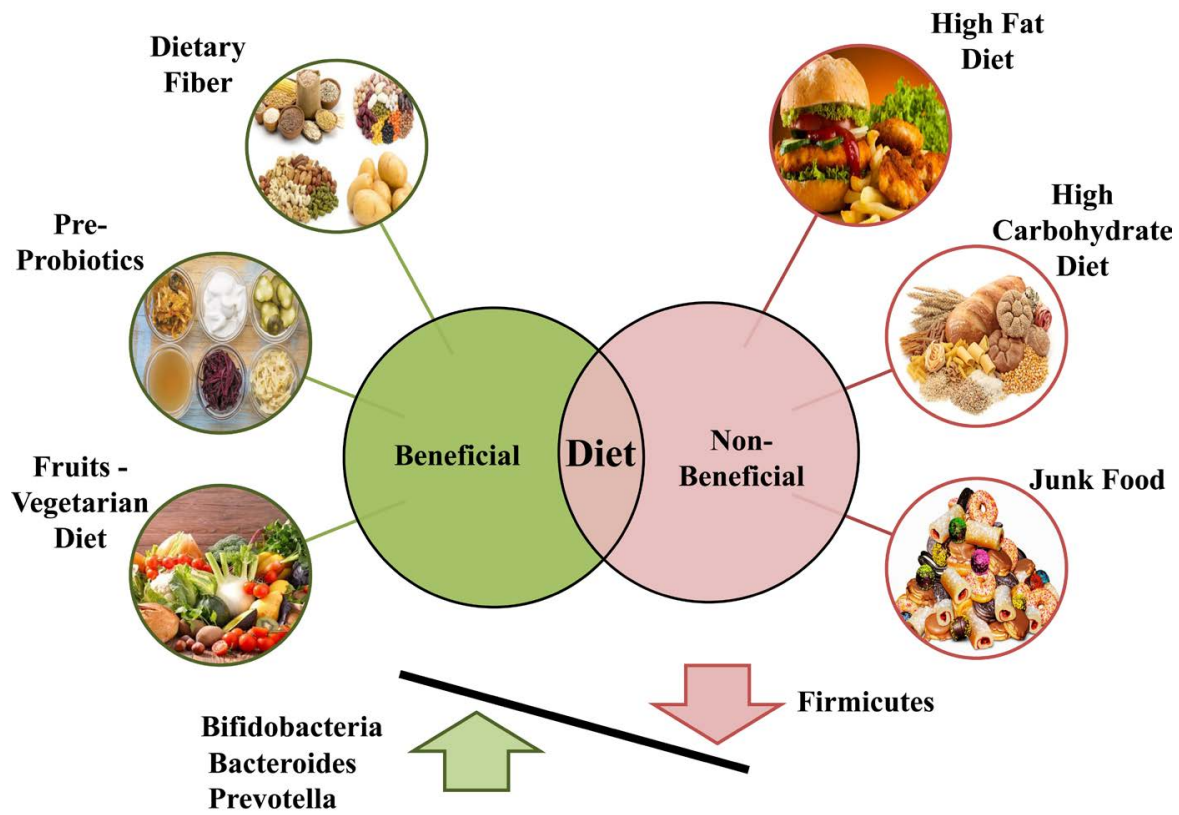

Figure 3. Illustrates the beneficial and non-beneficial diets shapes the composition of gut microbial population. 
pathways [45]. Activation of such signaling pathways influences the body metabolism, which regulates the energy homeostasis and ultimately ends up with obese or lean phenotype [46].

Diets mainly classified into beneficial and non-beneficial diet. Depends upon the nature, composition and the caloric value, diet influences the health status of the body and accordingly they are categorized into good or bad. Once the diet enters into the gut, microbiome composition changes promptly and shifts the metabolic pathway and immune response according to the diet type. Occurrence of many inflammatory and autoimmune diseases is mainly due to diet and the related beneficial/ non-beneficial microbes [36]. Maintaining beneficial microbial colony in the body is not an easy task, apart from diet, factors such as physical activity and lifestyle play a vital role in shaping the beneficial gut microbiota. Foods such as high caloric diet, high sugar/fat, western diet and junk foods have the potential to stimulate non-beneficial microbes where as beneficial diet such as pre-probiotic and fiber rich diet shows excessive ability in rejuvenating the beneficial microbiota [47].

In modern lifestyle, consumption of non-beneficial diets such as western diet, with high fat and sugar is increasing abruptly and intake of dietary fiber has dropped drastically [48]. Overconsumption of industrialized diet al.so affects the beneficial microbial community that has the impact on the homeostasis of the system [36]. Varadharajan et al. [49] reported that cafeteria diet highly influences the gut microbes in Sprague Dawley rats and showed variation in the Firmicutes, Bacteroidetes and Proteobacteria that leads to obesity. Diet rich in saturated fatty acid alters the intestinal flora and increases the ratio of gram-negative bacteria; this shift in the bacterial composition stimulates the production of lipopolysaccharides (LPS) that increase the gut permeability and leads to metabolic endotoxemia [50]. High sugar western diet such as soft drinks, pastries, desserts and white bread are high in energy content but low in nutritive value that alter the gut microbial metabolism and increase the risk of obesity, cardiovascular disease and diabetes [51].

Beneficial diets such as fiber rich, pre-probiotics and vegetarian diet encourage the growth of beneficial gut microbes that are needed to compensate the destructive effects of other factors in the host system. More than a century ago, the Nobel laureate Elie Metchnikoff [52] hypothesized that supplementation of lactic acid bacteria had beneficial health effect and supports extended longevity. Probiotics are living microorganisms that can modulate the gut microbiota and act to enhance the host health through precluding intestinal disorders [53]. Probiotics act on gut microbiota directly or indirectly and control the microbial dysbiosis in the gut; however, the mechanism remains unclear [54]. McNutty et al. [55] reported that adequate amount of yogurt does not alter the microbial community but considerably enhances deviation in the carbohydrate metabolizing enzymes. Prebiotics are non-digestible food components supports the fermentation process of beneficial gut microbiota. 
Prebiotics such as inulin, fructooligosaccarides, lactulose and galactooligosaccharides are generally considered for the enhancement of Lactobacillus and Bifidobacterium that produces short chain fatty acids (lactate and acetate) and contributes to the host health by enriching prebiotics through fermentation process [56]. Diets that are resistant to digestion but fermentable are of interest as prebiotics due to their prospective health benefits. Resistant starch is a prebiotic, the complex carbohydrate comparatively resistant to digestion in small intestine by intestinal enzymes. Depends upon the composition of resistant starch, the microbial population in the gut reacts differently and influences the proportion of Firmicutes and Bacteroidetes [57] [58]. When resistant starch enters the large intestine, short chain fatty acids such as butyrate are produced due to microbial fermentation; they have various health benefits act as an energy source for colonic epithelial cells and enhances the insulin sensitivity [59].

Various studies focused on other beneficial diets such as fruits, vegetables, fermentable dietary fibers and fish enriched with poly-unsaturated fatty acid suggesting that consumption of these diets improves the immune system as the immune cells responsible for the first line of host defense system [60]. In addition, these dietary nutrients play a major role in supporting interaction between the host and gut microbiome to regulate the gut epithelial dysbiosis, controlling allergic conditions and support the immune system to reduce inflammatory disorders. Micronutrients such as vitamins and minerals present in these diets play a vital role in production of organic molecules; however, deficiencies in vitamins and minerals might have a major impact in the metabolic pathways and cause health disorders [61].

\subsection{Age}

Aging is a multifactorial process affecting an extensive range of physiological, metabolic, genomic and immunological functions [62]. In earlier days, new born are believed to born free from microbes but recent research proved that infants are already exposed to different microbes in utero. Microbial colonization starts in the uterus of the mother and recent findings also revealed the presence of microbes in placenta [27], Colostrum, amniotic cavity [28], umbilical cord [29] and meconium [63]. The gut microbiota starts colonization at the time of birth after encountering with the maternal microbiomes, in the initial life, infants introduced to microbiome through various factors such as birth mode, exposure to the external environment, infant feeding, maternal lifestyle and others. Gut microbiome is tremendously diverse and intricate as a community occupying the gastrointestinal tract and they are inconsistent throughout in all the stages of the life. These deviations have great impact on the host health and contribute to metabolic disorders [64].

After infant stage, within 3 - 4 years of duration after birth the microbial community transformed into a community that is specific to adults [12] [65]. At this stage, myriad of life style changes such as food habit/malnutrition, physical 
activities, external factors etc., are the key factors shaping the gut microbial composition. Another significant shift in the diversity of the gut microbiome occurs in the adolescence stage due to hormonal changes and diet in addition to some metabolic changes. In adulthood, gut microbes alter when the host undergoes stress, change in life style or geographical location and biochemical/ metabolic disorders [66]. Finally, at elderly stage, there is a dramatic shift in the configuration of gut microbes due to food habit, medication, psychological disorder and weakened organ function. In general, aging related changes in the composition of gut microbiota are varying due to various factors like geographical location, lifestyle, diet etc. However, the role of gut microbial dysbiosis in aging and senescence-associated disorders remains unclear [64].

\subsection{Non-Dietary Lifestyle}

Non-dietary lifestyle has great impact on the gut microbiota and not very well studied [1]. Non-Dietary lifestyle such as smoking, alcohol consumption, stress, exercise, environmental factors and sedentary lifestyle are the major elements that shape the intestinal microbes.

\subsubsection{Smoking}

Cigarette smoking reported to be associated with lung cancer, however it is influence and studied extensively that it affects not only the lung tissue but also affects the gut microbiome [67]. Cigarette smoking affects intestinal gut microbial diversity, smoking affects the intestinal environment and this has a direct influence on gut microbiome and their interaction with the host [68]. Gut microbiome is susceptible to alteration due to smoking habit and/or inhalation of any nicotine components [69]. It has been reported that genera of Clostridium, Prevotella and Bacteroides as well phyla of Proteobacteria and Bacteroidetes were increased whereas genera of Bifidobateria and Lactococcus as well as phyla of Actinobacteria and Firmicutes were decreased in the fecal sample of the smokers. Due to intestinal mucin composition, changes in tight junction integrity, $\mathrm{pH}$ of gut and oxidative stress influences gut microbial population to induce a health condition, which resembles inflammatory bowel disorder and obesity. Lee et al. [70] reported that people who quit smoking for a significant period exhibits a great change in their gut microbial population, which resembles nonsmokers.

\subsubsection{Alcohol Consumption}

Worldwide, 2 billion people consume alcohol on a daily basis [71] and alcohol use is the fifth leading risk factor for premature death and disability among age group from 15 to 49 [72]. Consumption of alcohol also considered as a dietary factor that influence the gut microbial dysbiosis, which induces oxidative stress, intestinal hyper-permeability and mainly steatohepatitis. Leclercq et al. [73] suggested that crosstalk between gut microbes, microbial metabolite and the gut barrier functions in the alcohol dependent patients acquired high scores of depression, leaky gut syndrome, anxiety and alcohol craving that leads to the risk 
of relapse in gut-brain-liver interactions. Alteration in gut barrier function develops inflammation at the region of gut that stimulates the peripheral inflammation in liver that initiates inflammation response in brain significantly due to increased circulation of pro-inflammatory cytokines and activation of immune cells [74]. Gut and liver direct the signal molecules to brain through blood stream and influence the inflammation on the brain through the vagus nerve [75]. Some of the major gut derived peptides, such as ghrelin, GLP1 or PYY also highly influenced by alcohol behavior [75]. Alcohol dependence along with other diet and environmental disorders showed high impact on neurobiological pathways in the brain that involved in multiple metabolic disorders [76]. Regularizing the alcohol consumption, beneficial diet and active lifestyle might alter the gut microbial population, however rectifying injured tissue and the nervous system is a challenging task.

\subsubsection{Physical Exercise}

Exercise is the best means of protection against many chronic diseases including diabetes, obesity and intestinal bowl disorder. Regular physical exercise enhances the maintenance of the constant status of cardiovascular and brain health, which plays a progressive role in reducing body weight, improves glucose metabolism, energy homeostasis and regulation [77] [78]. Sedentary behavior along with western diet leads to increase in the size of the villi due to plasmacytoid and lymphocytic infiltrations and this can be prevented by exercise [79]. Matsumoto et al. [80] reported that voluntary exercise influences gut microbiota diversity in rats, and increase n-butyrate concentration that increases cecum diameter, which reduces colon disorders. Evans et al. [81] suggested regular physical exercise play a major role in the diet induced obesity mice model and the microbial composition is similar to that of lean mice. When compared with adult versus juvenile rats, exercise in juveniles promotes gut microbiota and improves the development of brain and regulation of metabolic pathways [82]. In older adults, exercise interventions can be associated with enriching gut microbiota and activation of metabolic pathways to prevent cardio-metabolic disorders [83].

\subsubsection{Stress}

Stress is a natural emotional feeling or physical challenge that linked to various physical disorders such as hypertension, depression, anxiety, heart attacks, stroke and some immune disturbances. Stress can directly act and induce immediate disturbances in gastrointestinal system (Peptic ulcer, irritable bowel syndrome, Ulcerative colitis) and on the skin (Allergies, rashes, atopic dermatitis). Due to stress, body releases respective hormones that regulate the heartbeat and breathing rates, which induce the muscles to respond accordingly. Recent research on stress physiology showed much interest in the stress related gut-brain axis signaling pathways and its disorders [84]. Van de Wouw et al. [85] suggested that short chain fatty acids, a novel nutrition derived from gut microbial 
fermentation of dietary fibers could alleviate the stress related disorders. Several mechanism has been involved that can transmit signals from the gut microbiota to brain. Signal from the gut epithelial cells activates vagus nerve and microbial antigens to induce B-cell response and production of short chain fatty acids and endocrine signaling events. Moreover, cross talk between gut-brain axis controls the neural signal process associated in stress-related responses [84]. Enriching beneficial gut microbiota through consumption of probiotics diet can help to reduce cortisol, a stress hormone [86]. Social stress and exercise-induced stress are some of the temporary stress that can be relieved by appropriate nutritional choice and good sleep [87].

\subsubsection{Medications}

Antibiotics and the non-antibiotic drugs become essential in the modern life and usage of these drugs can improve the health by curing and preventing various diseases and infections. Recent findings reported that use of antibiotics might affect the beneficial gut microbial population and their function that leads to several metabolic disorders [88]. Antibiotic treatment has been constantly successful for many years in treating various bacterial infections, but the development of antibiotic resistant bacteria creates several health issues and it persists in the gut for many years [89] [90]. According to Ferrer et al. [91] use of antibiotics alters the gut microbial homeostasis from the time of starting the drug, but their population stabilized back to the normal state at the end of the treatment. Antibiotic treatment on less abundant and little active gut bacteria becomes highly active and play a vital role in improving the interconnection between the liver and colon that stimulate to produce necessary molecules such as bile acids, hormone and other derivatives. In the same way non-Antibiotic drugs have also exhibited both beneficial and adverse effects on host health. Pharmaceutical agents that target human cells but not gut microbes also showed impact on changing the gut microbial population [92]. More elaborated animal model studies needed to understand the mechanism behind the interaction between the host, medication and the gut microbiome. Considering the tremendous beneficial role of gut microbiota and the way they easily disturbed due to antibiotic usage, Laxminarayan et al. [93] suggest that improving sanitation, expanding use of vaccines and controlling hospital infection are the main effective measures in reducing antibiotic usage.

\subsubsection{Geography}

The taxonomical variations of intestinal microbiota associates with specific geographical location and origin of the individual. Many reports suggest that gut microbial composition is influenced by diet, age, antibiotics and etc., but very few studies have been reported on explaining microbial diversity is intertwined with socio-economic, geographic and culture settings [94]. Even though, there is a significant variation in gut microbiota between the host species, geographical location based variations also received considerable attention. Suzuki and Wo- 
robey [95] reported that there is a significant association between gut microbiota and the geographical location of the individual and even their ancestors. Worldwide, diet plays a significant role in gut microbiome variations along with geographical location as the food preference varies from east to west that has a direct impact on microbiome composition. Moreover, the type of food consumption is tightly bound to cultural and agricultural development of the country that also influences the varied microbiome landscape in the gut. Nevertheless, microbial diversity differs between two individuals living in a same geographical region, same country and even between urban and rural area due to different food habits and socio-cultural practices [96].

\section{Role of Diet on Gut Microbiome in Host Health}

Various organs in the body are structured as per the function and the complex cellular mechanism and an interrelationship is maintained through combined effort of these critical organs. Same way intestinal flora plays a critical role and act as an organ in distinguishing the intestinal flora from the pathogenic microbes entering into the system. This tight control of the intestinal flora combined with cellular mechanism helps to maintain the vital physiological functions and structure of organs in the body as per their specific function. Even though research community, exemplifies the structure, function, metabolism and signaling pathways of the organs across the globe, one critical organ is overlooked all along in the scientific field that is nothing but microbes present in the intestinal tract and they are called "Gut Microbiota". There is no detailed description about microbiota's function, metabolism and impact on immune system but this gut microbes greatly contributing in body health [46]. Meanwhile, gut microbiota is composed of different group of microbes and each group act distinctively on their role and functions, however biologists still debating on whether the gut microbiota can be considered as a new organ or a system. To understand the exact role of gut microbiota in the body function, extensive study is needed to explore the genetic and functional aspects of the microbial community and this can be achieved by the recently developed metagenome analysis of the microbiota.

Population diversity of the microorganism in the human body varies from different parts of the intestine. Factors such as birth mode, feeding, diet, environmental factors, aging are various elements that influence the composition and diversity of the microbes, which could be beneficial or non-beneficial. Firmicutes, Bateroidetes, Proteobacteria and Actinobacteria are the four major phyla that shape the gut, showed great impact on host metabolism and immune system and contribute in breakdown of food and energy metabolism [97] [98]. Alteration of gut microbiota in the gut region leads to beneficial and non-beneficial effects. To resolve the impact of non-beneficial effects in the human body, the microbial composition needs to be reverted to normal via any one of the influencing factors. In recent decades, human as well as animal model studies played a major role in understanding the role of gut microbiota in health. Few 
studies are well explained about bacterial functions on host and energy expenditure via SCFA [99] [100], bile salt metabolism [101] [102], Liver-gut-brain axis [103] [104], immune signaling mechanism. However, a defined role and mechanism of the gut microbiome still remains unclear and needs more studies using animal models.

As previously discussed, gut microbiota is remarkably affected by various factors such as birth mode, feeding, host genetics, diet and environmental factors. However, diet constantly revealed as one of the major factors for intestinal dysbiosis and more than $50 \%$ of alteration of intestinal microbiota has been associated with dietary interventions [104]. After general digestion process in the stomach, undigested food reaches the gut, based on the nutritional composition of the diet, gut microbial community gets altered and this leads to the activation of various signaling and immunological pathways by producing microbial metabolites, vitamins and SCFA. Here, gut-brain-liver axis, the tri-directional communication network between the gastrointestinal, central nervous system and hepatic system plays a major role of the homeostasis in the body. In this, gut and brain interactions contributing more in bioactive, neural, hormonal and immunological signaling [105].

Most importantly two main mechanisms shape the gut microbiota either beneficial or non-beneficial towards the host health. As far as the development of obesity is concerned, 1) the role of SCFA, bacterial metabolite that synthesized by gut microbiota and 2) the role of LPS, a structural component from a group of gut microbiota are the main players contributing to the maintenance of host body health. Primarily, when undigested food (undigested carbohydrate/fat, dietary fiber, resistant starch, protein) from small intestine reaches the gut, the microbial composition of this undigested food influences the inhabitant microbes in the system. Microbes in cecum and colon region can able to synthesize enzymes that cannot be produced by host cells. Undigested foods are fermented and yield gut microbiota derived metabolites such as SCFA, phenolic acids, bile acids and tryptophan that are considered important and essential for host health [99]. Among these, SCFA is the main fermented product, which includes formic, acetic, propionic, butyric and valeric acid. Acetate, propionate and butyrate are the SCFA synthesized predominantly from different pathways such as Wood-Ljungdahl, acrylate and butyryl-CoA pathway respectively [106] [107]. Acetate and propionate are the main metabolites synthesized by Bacteroidetes, whereas butyrate by Firmicutes. Butyrate's mainly supports as an important energy source for colonocytes whereas acetate and propionate absorbed by the liver and initiates lipogenesis and gluconeogenesis. Absorption of these SCFA by intestinal epithelial cells achieved via non-ionic diffusion, carrier mediated transportation and exchange with bicarbonate [108]. During SCFA absorption, alteration in the $\mathrm{pH}$ of the colon modifies the composition of gut microbiota, and due to the exchange of bicarbonate leads to $\mathrm{pH}$ variation. High concentration of SCFA, low $\mathrm{pH}$ in the lumen prevents the overgrowth of $\mathrm{pH}$ sensitive bacteria. Butyrate producing 
bacteria (Firmicutes) covers $20 \%$ of total population at $\mathrm{pH} 5.5$ however, acetate and propionate producers (Bacteroidetes) dominate when $\mathrm{pH}$ increases to 6.5 due to less production of SCFA [109].

Above-mentioned SCFA is involved in several interesting mechanism of host health by acting combined or independent manner. Hijova and Chmelarova [110] reported that SCFA synthesis in large intestine showed in the order of acetate $>$ propionate $>$ butyrate and found to be 3:1:1 ratio. However, acetate and propionate are synthesized in both ileum and colon while butyrate mainly in colon and cecum [111]. Depending upon the absorption site (transverse, ascending, descending and sigmoid colon), the absorbed SCFA transported into various vein (Mesenteric vein, portal vein and inferior vena cava) and entering into the circulation influencing the function and metabolism of various tissues (Adipose tissue, skeletal muscles and liver) [108] [112]. From all of these SCFA, Butyrate is the major energy source of colonocytes and is oxidized into acetyl-CoA, which successively produces ATP through Kreb's cycle. In addition to butyrate production, gut microbiota influence the enzymes involved in colonocyte-mitochondrial SCFA-oxidative reactions. Moreover, butyrate also involved in the controlling of cellular apoptosis, proliferation-differentiation, diet-induced obesity and metabolic endotoxemia [101] [113]. Further, butyrate improves the intestinal gluconeogenesis, insulin sensitivity and energy expenditure that favors the reduction of obese condition. Anti-inflammatory potential of butyrate can able to ease the metabolic functions and increase the gut permeability [114]. Butyrate also stimulates the anorexigenic gut hormones that regulate the body weight by controlling food intake [115]. Besides these antiobesogenic properties, butyrate also increases the expression of leptin synthesis and protect against colon cancer [110] [113]. Like butyrate, propionate also protects against diet-induced obesity without causing hypophagia, regulates body weight, reduce food intake, increase leptin synthesis and act as precursor for gluconeogenesis [110] [115] [116]. Propionate also reduces the cholesterol synthesis and inhibiting the acetyl-CoA synthetase and inhibits the resistin expression in adipose tissue. Dominant acetate absorbed promptly due to higher percentage and shorter in size (C2:0). Acetate is a substrate for lipogenesis and cholesterol synthesis in liver and other tissues. Acetate also involved in the protection of diet-induced obesity without causing hypophagia and the action is self-regulating without any effect on gut hormone. Propionate protects against diet-induced obesity without causing hypophagia and regulating the serum cholesterol synthesized by acetate [113] [116]. These entire three SCFA are interplay between their function and influence the other metabolic, molecular, immunological pathways and microbial components to drive the host health along with other environmental factors. In addition to SCFA metabolism, bile salt metabolism also increases the energy expenditure and protects from diet-induced obesity [117]. Alterations in the gut microbiota influences the choline metabolism, helps in glucose homeostasis and again they influence the occurrence of cardiovascular diseases [118]. 
Secondly, LPS a bacterial component associated with low-grade inflammation and innate immune response can have major complications in host health. Gram-negative bacteria present in the gut lumen are the sole source of LPS. LPS is a glycolipid composed of a hydrophobic lipid A domain, which is attached to the outer membrane of the Gram-negative bacterial cell wall, a core and distal oligosaccharide along with two phosphate molecules that act as endotoxin [119]. Gut mucosa layer plays a central role in digestion and absorption of nutrients and it provides a physical barrier to prevent the entry of bacteria from lumen, toxins, other pathogens or any allergens into the body system. The gut epithelial layer is the primary defense against an antagonistic environment within the gut lumen. Dysfunction of intestinal barrier leads to easy entry of antigens into the body tissues. In general, LPS concentrations are higher in the lumen region and very low or undetectable in the circulating blood plasma [120]. Gut lumen LPS is not capable of entering healthy and intact gut epithelial barrier. However, LPS can able to enter into the body system through blood circulation in the defective gut tight junction barrier [121]. High fat diet alters the gut microbiota and increases the gram-negative bacterial composition, which in turn increases the LPS production that disturbs the gut permeability finally leads to "metabolic endotoxemia" [122].

Normally, LPS released from live bacteria during growth and cell division as a cell wall component of dead bacterial cell [123]. Due to the gut dysbiosis, existence of LPS concentration in the lumen could be higher and influence various signaling pathways that can alter immune response to produce pro-inflammatory cytokines. In addition, LPS enters by transcellular transport through intestinal epithelial microfold cells (M-cells) that are permeable to macromolecule and various antigens [124], through Myeloid differentiation protein-2 (MD-2) mechanism [125] they can also be transported by chylomicron to the basolateral membrane [126]. Neal et al. [125] reported that TLR4 present on the apical surface on enterocytes could internalize the gram-negative bacteria through phagocytosis and enhancing the binding and transportation of LPS [127]. Furthermore, LPS can also be transported via paracellular pathway across the intestinal epithelial tight junction. Cani et al. [128] reported that increased LPS absorption could affect the tight junction protein expression, which leads to increased gut permeability; in contrast, Bifidobacterium composition can strengthen the tight junction protein expression. Varadharajan et al. [129] and Alasmar et al. [130] reported that gut microbiota, biochemical parameters and inflammatory markers variations in cafeteria diet fed Sprague Dawley rats. Cafeteria diet induces obesity and affects the endothelial function that alters the immune response [131] and this might be due to gut microbial dysbiosis. All above said mechanisms along with the other environmental factors, exerting their influence on cellular immune response affect host health. Scheme 1 explains the overall hypothesis behind gut microbiota dysbiosis. Undigested food plays a major role in gut microbial dysbiosis and the proposed hypothesis explains the possible 


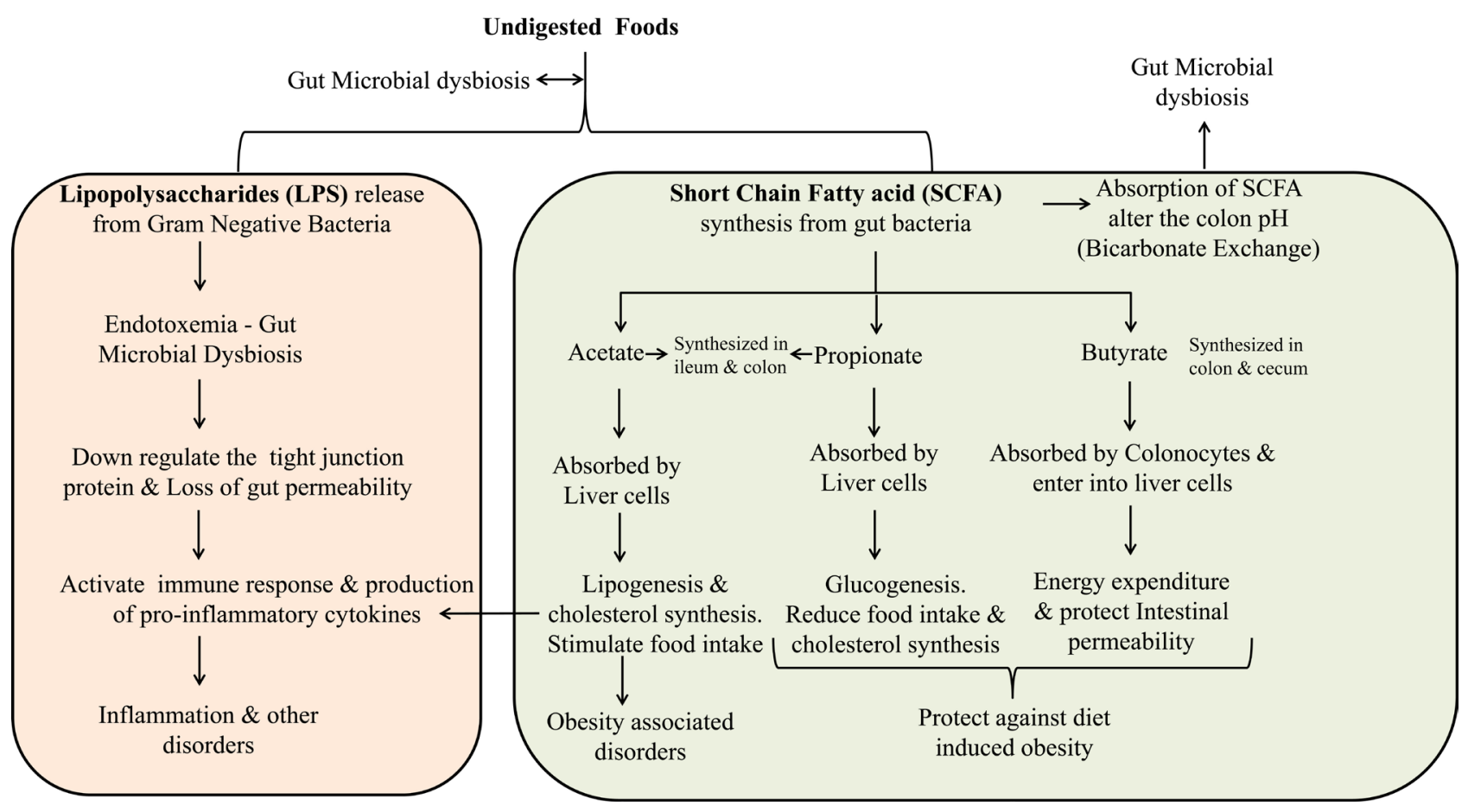

Scheme 1. Explains the overall mechanism behind the short chain fatty acids and Lipopolysaccharides synthesis by gut microbiota.

pathways due to gut microbial dysbiosis that has impact on host health.

\section{Rodent Models Gut Microbiome Research}

Animal models play a vital role in biomedical research to prove hypothesis and derive therapeutic modalities. In past two decades, gut microbiome research is thriving to explore the role and mechanism behind intestinal homeostasis. Gastrointestinal tract consists of complex microbial communities and it is well known that gut microbiome plays an essential role in the food metabolism, immune response and various metabolic disorders [13]. Gut microbial composition in both human and rodents are similar at phylum level whereas some differences there in the genera level [132]. Rodent models are very similar in both physiological and molecular level and used extensively in microbiome research to understand the interplay between host physiologies and gut microbial influence. To study all the pathophysiological changes in human is difficult in terms of time and expense. Hence, most of the researchers prefer animal models particularly rodent models. More than hundreds of rodent models including transgenic knock-in and knockout models, germ free models are available for microbiome, molecular and metabolic research [133]. In recent past, animal models used regularly in obesity research, both genetic and non-genetic models are available to study various functional aspects. The choice of the model depends on the nature and aim of the study such as testing specific molecular target or for future therapeutics. Table 1 explains available animal models in gut microbiota research.

The paradigm of change in gut microbiota landscape and their impact on animal and human health raised the interest and awareness among the research 
Table 1. Rodent models in the microbiome research.

\begin{tabular}{|c|c|c|c|}
\hline Rodent Type & Rodent Model & Research Application & References \\
\hline Mice & ob/ob mouse & Obese mouse & Coleman [137] \\
\hline Mice & $\mathrm{db} / \mathrm{db}$ mouse & Diabetic mouse & Coleman [137] \\
\hline Mice & s/s mouse & $\begin{array}{l}\text { Genetically engineered animal model of leptin } \\
\text { receptor deficiency }\end{array}$ & Bates et al., [138] \\
\hline Rat & Leptin receptor-deficient rats & Leptin-resistant obesity & Bates et al., [138] \\
\hline Rat & $\mathrm{fa} /$ fa-fatty rat & Extracellular domain of the leptin receptor obesity & Bray and York, [139] \\
\hline Rat & Zucker Diabetic Fatty (ZDF) rats & Obesity & Zierath et al., [140] \\
\hline Rat & Wistar Kyoto fatty rat (WDF rat) & Obesity and co-morbidities & Ikeda et al., [141] \\
\hline Mouse & POMC knockout mouse & Deficit downstream of the brain leptin receptor & O’Rahilly [142] \\
\hline Rat & Diet-induced obese (DIO) & Obesity & Levin and Dunn-Meynell [143] \\
\hline Rat & Diet-resistant (DR) & Obesity & Levin and Dunn-Meynell [143] \\
\hline Rat & Cafeteria diet-induced obesity (CD) & Obesity & Rogers and Blundell [144] \\
\hline Rat & High-fat diet-induced obesity (HF) & Obesity & Willett and Leibel [145] \\
\hline Mice & New Zealand obese mouse (NZO) & Obese ans type- 2 diabetes & Joost [146] \\
\hline Mice & Age-related obesity in mice (LOO) (C57B6) & Obesity & Becskei et al., [147] \\
\hline Rat and Mice & $\begin{array}{l}\text { Early postnatal overfeeding induced obesity; } \\
\text { rearing in small litters }\end{array}$ & Obesity & Faust et al., [148] \\
\hline Mice & Glucose transporter subtype 4 (GLUT4) & Obesity & Shepherd et al., [147] \\
\hline Rat & GH-deficient dwarf rat & Deficient growth hormone (GH) & Davies et al., [150] \\
\hline Rat & Diet-Induced obesity & Obesity & Hamda et al. [151] \\
\hline Rat & Juvenile obesity animal model & Obesity & Sandra and Hamda [152] \\
\hline
\end{tabular}

community, however finding a suitable animal model to study the microbiota changes on human health is a challenge [134]. Use of animal models with different microbiota community and complexity might highlight the interrelation of how host genes affect the microbiome [135]. In human body the dominant phyla of microbiota are Firmicutes and Bacteroidetes. Rat model has more similar baseline of Firmicutes:Bacteroidetes and similar phylogenetic ratio to human fecal microbiota than mice. However, rat models have limitation due to minimal genetic variations hence studies of disease specific models are not possible. In mice the microbiota structure is almost similar to human with dominant phyla constitutes Firmicutes and Bacteroidetes [136]. The interest on studying microbiota in mice models are steadily increasing because disease specific mice models can be easily created to study the effect of disease mechanism on microbiota diversity and the host response. When studying human disease or physiology using mice model, the similarity and difference between the two species need to be accounted to draw a general conclusion including the translatability of findings. Studying microbiota changes using gene-targeted mice for example can be helpful in understanding the intervention factors that otherwise cannot be studied in 
human subjects [134]. Even though mice and human gut gastrointestinal anatomy and physiology are almost similar, researchers need to be more cautious of their differences as well. Especially in human, the higher metabolic rate, complexity in diet and response towards environmental can never be modeled and studied using rodents [134].

\section{Future Research}

Knowledge on microbiome has been dramatically improved in the recent past and this helps us in identifying the function and mechanism of these microbes in maintaining the host health. It is proven that they are not only as a part of a host system but participates in the host metabolism and other functions. Microbiota such as Firmicutes and Bacteroidetes are identified with their association with certain host function. It is possible now to manipulate them towards normal function and better health. This review highlights some of the gut microbiota dysbiosis due to various factors apart from diet composition and their impact on obese phenotype. As the gut microbiota functions as a key regulator of host function, it can be used as a therapeutic target for the development of personalized medicine. Already fecal transplant procedures are in practice towards this end. Microbiome based disease identification can be developed; this can predict the disease in advance to initiate the early therapeutic intervention. Future research needs to focus more on how the host microbiome composition can be personalized to develop appropriate therapeutics.

\section{Acknowledgements}

The authors acknowledge Qatar University-VP for Research and Graduate studies for the financial support via graduate assistantship provided to Mrs. Reem Moath Al Asmar.

\section{Conflicts of Interest}

The authors declare no conflict of interest.

\section{References}

[1] Conlon, M. and Bird, A. (2015) The Impact of Diet and Lifestyle on Gut Microbiota and Human Health. Nutrients, 7, 17-44. https://doi.org/10.3390/nu7010017

[2] Fontané, L., Benaiges, D., Goday, A., Llauradó, G. and Pedro-Botet, J. (2018) Influence of the Microbiota and Probiotics in Obesity. Clínica e Investigación en Arteriosclerosis, 30, 271-279. https://doi.org/10.1016/j.arteri.2018.03.004

[3] Rajoka, M.S.R., Shi, J., Mehwish, H.M., Zhu, J., Li, Q., Shao, D., Huang, Q. and Yang, H. (2017) Interaction between Diet Composition and Gut Microbiota and Its Impact on Gastrointestinal Tract Health. Food Science and Human Wellness, 6, 121-130. https://doi.org/10.1016/j.fshw.2017.07.003

[4] Ley, R.E., Bäckhed, F., Turnbaugh, P., Lozupone, C.A., Knight, R.D. and Gordon, J.I. (2005) Obesity Alters Gut Microbial Ecology. Proceedings of the National Academy of Sciences of the United States of America, 102, 11070-11075. 
https://doi.org/10.1073/pnas.0504978102

[5] Clarke, S.F., Murphy, E.F., Nilaweera, K., Ross, P.R., Shanahan, F., O’Toole, P.W. and Cotter, P.D. (2012) The Gut Microbiota and Its Relationship to Diet and Obesity: New Insights. Gut Microbes, 3, 186-202. https://doi.org/10.4161/gmic.20168

[6] Mozeš, Š., Bujňáková, D., Šefč́́ková, Z. and Kmet', V. (2008) Developmental Changes of Gut Microflora and Enzyme Activity in Rat Pups Exposed to Fat-Rich Diet. $O b$ esity, 16, 2610-2615. https://doi.org/10.1038/oby.2008.435

[7] Wong, J.M., De Souza, R., Kendall, C.W., Emam, A. and Jenkins, D.J. (2006) Colonic Health: Fermentation and Short Chain Fatty Acids. Journal of Clinical Gastroenterology, 40, 235-243. https://doi.org/10.1097/00004836-200603000-00015

[8] Flint, H.J., Duncan, S.H., Scott, K.P. and Louis, P. (2015) Links between Diet, Gut Microbiota Composition and Gut Metabolism. Proceedings of the Nutrition Society, 74, 13-22. https://doi.org/10.1017/S0029665114001463

[9] Morrison, D.J. and Preston, T. (2016) Formation of Short Chain Fatty Acids by the Gut Microbiota and Their Impact on Human Metabolism. Gut Microbes, 7, 189-200. https://doi.org/10.1080/19490976.2015.1134082

[10] Flint, H.J. (2012) The Impact of Nutrition on the Human Microbiome. Nutrition Reviews, 70, S10-S13. https://doi.org/10.1111/j.1753-4887.2012.00499.x

[11] Yatsunenko, T., Rey, F.E., Manary, M.J., Trehan, I., Dominguez-Bello, M.G., Contreras, M., Magris, M., Hidalgo, G., Baldassano, R.N., Anokhin, A.P. and Heath, A.C. (2012) Human Gut Microbiome Viewed across Age and Geography. Nature, 486, 222-227. https://doi.org/10.1038/nature11053

[12] Clemente, J.C., Ursell, L.K., Parfrey, L.W. and Knight, R. (2012) The Impact of the Gut Microbiota on Human Health: An Integrative View. Cell, 148, 1258-1270. https://doi.org/10.1016/j.cell.2012.01.035

[13] Bäckhed, F., Fraser, C.M., Ringel, Y., Sanders, M.E., Sartor, R.B., Sherman, P.M., Versalovic, J., Young, V. and Finlay, B.B. (2012) Defining a Healthy Human Gut Microbiome: Current Concepts, Future Directions, and Clinical Applications. Cell Host \& Microbe, 12, 611-622. https://doi.org/10.1016/j.chom.2012.10.012

[14] Xu, X., Xu, P., Ma, C., Tang, J. and Zhang, X. (2013) Gut Microbiota, Host Health, and Polysaccharides. Biotechnology Advances, 31, 318-337.

https://doi.org/10.1016/j.biotechadv.2012.12.009

[15] Manrique, P., Bolduc, B., Walk, S.T., van der Oost, J., de Vos, W.M. and Young, M.J. (2016) Healthy Human Gut Phageome. Proceedings of the National Academy of Sciences of the United States of America, 113, 10400-10405. https://doi.org/10.1073/pnas.1601060113

[16] Costello, E.K., Stagaman, K., Dethlefsen, L., Bohannan, B.J. and Relman, D.A. (2012) The Application of Ecological Theory toward an Understanding of the Human Microbiome. Science, 336, 1255-1262. https://doi.org/10.1126/science.1224203

[17] Orr, M.R., Kocurek, K.M. and Young, D.L. (2018) Gut Microbiota and Human Health: Insights from Ecological Restoration. The Quarterly Review of Biology, 93, 73-90. https://doi.org/10.1086/698021

[18] Hooper, L.V., Littman, D.R. and Macpherson, A.J. (2012) Interactions between the Microbiota and the Immune System. Science, 336, 1268-1273. https://doi.org/10.1126/science.1223490

[19] Turner, J.R. (2009) Intestinal Mucosal Barrier Function in Health and Disease. Nature Reviews Immunology, 9, 799-809. https://doi.org/10.1038/nri2653

[20] Johansson, M.E., Phillipson, M., Petersson, J., Velcich, A., Holm, L. and Hansson, 
G.C. (2008) The Inner of the Two Muc2 Mucin-Dependent Mucus Layers in Colon Is Devoid of Bacteria. Proceedings of the National Academy of Sciences of the United States of America, 105, 15064-15069. https://doi.org/10.1073/pnas.0803124105

[21] Gallo, R.L. and Hooper, L.V. (2012) Epithelial Antimicrobial Defence of the Skin and Intestine. Nature Reviews Immunology, 12, 503-516. https://doi.org/10.1038/nri3228

[22] Van der Heijden, P.J., Stok, W. and Bianchi, A.T. (1987) Contribution of Immunoglobulin-Secreting Cells in the Murine Small Intestine to the Total Background Immunoglobulin Production. Immunology, 62, 551-555.

[23] Falony, G., Joossens, M., Vieira-Silva, S., Wang, J., Darzi, Y., Faust, K., Kurilshikov, A., Bonder, M.J., Valles-Colomer, M., Vandeputte, D. and Tito, R.Y. (2016) Population-Level Analysis of Gut Microbiome Variation. Science, 352, 560-564. https://doi.org/10.1126/science.aad3503

[24] Lamont, R.F., Sobel, J.D., Akins, R.A., Hassan, S.S., Chaiworapongsa, T., Kusanovic, J.P. and Romero, R. (2011) The Vaginal Microbiome: New Information about Genital Tract Flora Using Molecular Based Techniques. BJOG: An International Journal of Obstetrics \& Gynaecology, 118, 533-549.

https://doi.org/10.1111/j.1471-0528.2010.02840.x

[25] Aagaard, K., Riehle, K., Ma, J., Segata, N., Mistretta, T.A., Coarfa, C., Raza, S., Rosenbaum, S., Van den Veyver, I., Milosavljevic, A. and Gevers, D. (2012) A Metagenomic Approach to Characterization of the Vaginal Microbiome Signature in Pregnancy. PLOS ONE, 7, e36466. https://doi.org/10.1371/journal.pone.0036466

[26] Koren, O., Goodrich, J.K., Cullender, T.C., Spor, A., Laitinen, K., Bäckhed, H.K., Gonzalez, A., Werner, J.J., Angenent, L.T., Knight, R. and Bäckhed, F. (2012) Host Remodeling of the Gut Microbiome and Metabolic Changes during Pregnancy. Cell, 150, 470-480. https://doi.org/10.1016/j.cell.2012.07.008

[27] Aagaard, K., Ma, J., Antony, K.M., Ganu, R., Petrosino, J. and Versalovic, J. (2014) The Placenta Harbors a Unique Microbiome. Science Translational Medicine, 6, 237ra65-237ra65. https://doi.org/10.1126/scitranslmed.3008599

[28] Collado, M.C., Rautava, S., Aakko, J., Isolauri, E. and Salminen, S. (2016) Human Gut Colonisation May Be Initiated in Utero by Distinct Microbial Communities in the Placenta and Amniotic Fluid. Scientific Reports, 6, 23129.

https://doi.org/10.1038/srep23129

[29] Jiménez, E., Fernández, L., Marín, M.L., Martín, R., Odriozola, J.M., Nueno-Palop, C., Narbad, A., Olivares, M., Xaus, J. and Rodríguez, J.M. (2005) Isolation of Commensal Bacteria from Umbilical Cord Blood of Healthy Neonates Born by Cesarean Section. Current Microbiology, 51, 270-274.

https://doi.org/10.1007/s00284-005-0020-3

[30] Francino, M.P. (2018) Birth Mode-Related Differences in Gut Microbiota Colonization and Immune System Development. Annals of Nutrition and Metabolism, 73, 12-16. https://doi.org/10.1159/000490842

[31] Cabrera-Rubio, R., Collado, M.C., Laitinen, K., Salminen, S., Isolauri, E. and Mira, A. (2012) The Human Milk Microbiome Changes over Lactation and Is Shaped by Maternal Weight and Mode of Delivery. The American Journal of Clinical Nutrition, 96, 544-551. https://doi.org/10.3945/ajcn.112.037382

[32] Boix-Amorós, A., Collado, M.C. and Mira, A. (2016) Relationship between Milk Microbiota, Bacterial Load, Macronutrients, and Human Cells during Lactation. Frontiers in Microbiology, 7, 492. https://doi.org/10.3389/fmicb.2016.00492 
[33] Ardissone, A.N., Diomel, M., Davis-Richardson, A.G., Rechcigl, K.T., Li, N., Drew, J.C., Murgas-Torrazza, R., Sharma, R., Hudak, M.L., Triplett, E.W. and Neu, J. (2014) Meconium Microbiome Analysis Identifies Bacteria Correlated with Premature Birth. PLoS ONE, 9, e90784. https://doi.org/10.1371/journal.pone.0090784

[34] Willyard, C. (2018) Could Baby's First Bacteria Take Root before Birth? Nature, 553, 264-266. https://doi.org/10.1038/d41586-018-00664-8

[35] de Agüero, M.G., Ganal-Vonarburg, S.C., Fuhrer, T., Rupp, S., Uchimura, Y., Li, H., Steinert, A., Heikenwalder, M., Hapfelmeier, S., Sauer, U. and McCoy, K.D. (2016) The Maternal Microbiota Drives Early Postnatal Innate Immune Development. Science, 351, 1296-1302. https://doi.org/10.1126/science.aad2571

[36] Turnbaugh, P.J., Hamady, M., Yatsunenko, T., Cantarel, B.L., Duncan, A., Ley, R.E., Sogin, M.L., Jones, W.J., Roe, B.A., Affourtit, J.P. and Egholm, M. (2009) A Core Gut Microbiome in Obese and Lean Twins. Nature, 457, 480.

https://doi.org/10.1038/nature07540

[37] Goodrich, J.K., Waters, J.L., Poole, A.C., Sutter, J.L., Koren, O., Blekhman, R. Beaumont, M., Van Treuren, W., Knight, R., Bell, J.T. and Spector, T.D. (2014) Human Genetics Shape the Gut Microbiome. Cell, 159, 789-799. https://doi.org/10.1016/j.cell.2014.09.053

[38] Henao-Mejia, J., Elinav, E., Jin, C., Hao, L., Mehal, W.Z., Strowig, T., Thaiss, C.A., Kau, A.L., Eisenbarth, S.C., Jurczak, M.J. and Camporez, J.P. (2012) Inflammasome-Mediated Dysbiosis Regulates Progression of NAFLD and Obesity. Nature, 482, 179-185. https://doi.org/10.1038/nature10809

[39] Peng, J., Narasimhan, S., Marchesi, J.R., Benson, A., Wong, F.S. and Wen, L. (2014) Long Term Effect of Gut Microbiota Transfer on Diabetes Development. Journal of Autoimmunity, 53, 85-94. https://doi.org/10.1016/j.jaut.2014.03.005

[40] Goodrich, J.K., Davenport, E.R., Waters, J.L., Clark, A.G. and Ley, R.E. (2016) Cross-Species Comparisons of Host Genetic Associations with the Microbiome. Science, 352, 532-535. https://doi.org/10.1126/science.aad9379

[41] Singh, R.K., Chang, H.W., Yan, D., Lee, K.M., Ucmak, D., Wong, K., Abrouk, M., Farahnik, B., Nakamura, M., Zhu, T.H. and Bhutani, T. (2017) Influence of Diet on the Gut Microbiome and Implications for Human Health. Journal of Translational Medicine, 15, 73. https://doi.org/10.1186/s12967-017-1175-y

[42] Ley, R.E., Hamady, M., Lozupone, C., Turnbaugh, P.J., Ramey, R.R., Bircher, J.S., Schlegel, M.L., Tucker, T.A., Schrenzel, M.D., Knight, R. and Gordon, J.I. (2008) Evolution of Mammals and Their Gut Microbes. Science, 320, 1647-1651. https://doi.org/10.1126/science.1155725

[43] Muegge, B.D., Kuczynski, J., Knights, D., Clemente, J.C., González, A., Fontana, L., Henrissat, B., Knight, R. and Gordon, J.I. (2011) Diet Drives Convergence in Gut Microbiome Functions across Mammalian Phylogeny and within Humans. Science, 332, 970-974. https://doi.org/10.1126/science.1198719

[44] Gill, S.R., Pop, M., DeBoy, R.T., Eckburg, P.B., Turnbaugh, P.J., Samuel, B.S., Gordon, J.I., Relman, D.A., Fraser-Liggett, C.M. and Nelson, K.E. (2006) Metagenomic Analysis of the Human Distal Gut Microbiome. Science, 312, 1355-1359. https://doi.org/10.1126/science.1124234

[45] Bäckhed, F., Ley, R.E., Sonnenburg, J.L., Peterson, D.A. and Gordon, J.I. (2005) Host-Bacterial Mutualism in the Human Intestine. Science, 307, 1915-1920. https://doi.org/10.1126/science.1104816

[46] O'Hara, A.M. and Shanahan, F. (2006) The Gut Flora as a Forgotten Organ. EMBO Reports, 7, 688-693. https://doi.org/10.1038/sj.embor.7400731 
[47] Ash, C. and Mueller, K. (2016) Manipulating the Microbiota. Science, 352, 530-531. https://doi.org/10.1126/science.352.6285.530

[48] Hartley, L., May, M.D., Loveman, E., Colquitt, J.L. and Rees, K. (2016) Dietary Fibre for the Prevention of Cardiovascular Disease. Cochrane Database of Systematic Reviews, 1, CD011472. https://doi.org/10.1002/14651858.CD011472.pub2

[49] Varadharajan, K., Shanmugakonar, M., Das, S.C. and Al-Naemi, H.A. (2018) Gut Microbiota Dysbiosis in Cafeteria Diet Fed Sprague Dawley Rats. Advances in Microbiology, 8, 975-993. https://doi.org/10.4236/aim.2018.812066

[50] Moreira, A.P.B., Texeira, T.F.S., Ferreira, A.B., Peluzio, M.D.C.G. and Alfenas, R.D.C.G. (2012) Influence of a High-Fat Diet on Gut Microbiota, Intestinal Permeability and Metabolic Endotoxemia. British Journal of Nutrition, 108, 801-809. https://doi.org/10.1017/S0007114512001213

[51] Sonnenburg, E.D. and Sonnenburg, J.L. (2014) Starving Our Microbial Self: The Deleterious Consequences of a Diet Deficient in Microbiota-Accessible Carbohydrates. Cell Metabolism, 20, 779-786. https://doi.org/10.1016/j.cmet.2014.07.003

[52] Metchnikoff, E. and Metchnikoff, I. (1908) The Prolongation of Life. GP Putnam's Sons, New York, 234-301.

[53] Ringel, Y., Quigley, E.M. and Lin, H.C. (2012) Using Probiotics in Gastrointestinal Disorders. The American Journal of Gastroenterology Supplements, 1, 34.

[54] O'Toole, P.W. and Cooney, J.C. (2008) Probiotic Bacteria Influence the Composition and Function of the Intestinal Microbiota. Interdisciplinary Perspectives on Infectious Diseases, 2008, Article ID: 175285. https://doi.org/10.1155/2008/175285

[55] McNulty, N.P., Yatsunenko, T., Hsiao, A., Faith, J.J., Muegge, B.D., Goodman, A.L., Henrissat, B., Oozeer, R., Cools-Portier, S., Gobert, G. and Chervaux, C. (2011) The Impact of a Consortium of Fermented Milk Strains on the Gut Microbiome of Gnotobiotic Mice and Monozygotic Twins. Science Translational Medicine, 3, 106ra106. https://doi.org/10.1126/scitranslmed.3002701

[56] Adamberg, S., Sumeri, I., Uusna, R., Ambalam, P., Kondepudi, K.K., Adamberg, K., Wadström, T. and Ljungh, A. (2014) Survival and Synergistic Growth of Mixed Cultures of Bifidobacteria and Lactobacilli Combined with Prebiotic Oligosaccharides in a Gastrointestinal Tract Simulator. Microbial Ecology in Health and Disease, 25, 23062. https://doi.org/10.3402/mehd.v25.23062

[57] Martínez, I., Kim, J., Duffy, P.R., Schlegel, V.L. and Walter, J. (2010) Resistant Starches Types 2 and 4 Have Differential Effects on the Composition of the Fecal Microbiota in Human Subjects. PLOS ONE, 5, e15046. https://doi.org/10.1371/journal.pone.0015046

[58] Upadhyaya, B., McCormack, L., Fardin-Kia, A.R., Juenemann, R., Nichenametla, S., Clapper, J., Specker, B. and Dey, M. (2016) Impact of Dietary Resistant Starch Type 4 on Human Gut Microbiota and Immunometabolic Functions. Scientific Reports, 6, 28797. https://doi.org/10.1038/srep28797

[59] Gao, Z., Yin, J., Zhang, J., Ward, R.E., Martin, R.J., Lefevre, M., Cefalu, W.T. and Ye, J. (2009) Butyrate Improves Insulin Sensitivity and Increases Energy Expenditure in Mice. Diabetes, 58, 1509-1517. https://doi.org/10.2337/db08-1637

[60] Qiu, Y., Peng, K., Liu, M., Xiao, W. and Yang, H. (2016) CD8 $\alpha \alpha$ TCR $\alpha \beta$ Intraepithelial Lymphocytes in the Mouse Gut. Digestive Diseases and Sciences, 61, 1451-1460. https://doi.org/10.1007/s10620-015-4016-y

[61] Statovci, D., Aguilera, M., MacSharry, J. and Melgar, S. (2017) The Impact of Western Diet and Nutrients on the Microbiota and Immune Response at Mucosal Interfaces. Frontiers in Immunology, 8, 838. https://doi.org/10.3389/fimmu.2017.00838 
[62] Kenyon, C.J. (2010) The Genetics of Ageing. Nature, 464, 504-512. https://doi.org/10.1038/nature08980

[63] Nagpal, R., Tsuji, H., Takahashi, T., Kawashima, K., Nagata, S., Nomoto, K. and Yamashiro, Y. (2016) Sensitive Quantitative Analysis of the Meconium Bacterial Microbiota in Healthy Term Infants Born Vaginally or by Cesarean Section. Frontiers in Microbiology, 7, 1997. https://doi.org/10.3389/fmicb.2016.01997

[64] Nagpal, R., Mainali, R., Ahmadi, S., Wang, S., Singh, R., Kavanagh, K., Kitzman, D.W., Kushugulova, A., Marotta, F. and Yadav, H. (2018) Gut Microbiome and Aging: Physiological and Mechanistic Insights. Nutrition and Healthy Aging, 4, 267-285. https://doi.org/10.3233/NHA-170030

[65] Bergström, A., Skov, T.H., Bahl, M.I., Roager, H.M., Christensen, L.B., Ejlerskov, K.T., Mølgaard, C., Michaelsen, K.F. and Licht, T.R. (2014) Establishment of Intestinal Microbiota during Early Life: A Longitudinal, Explorative Study of a Large Cohort of Danish Infants. Applied and Environmental Microbiology, 80, 2889-2900. https://doi.org/10.1128/AEM.00342-14

[66] McVey Neufeld, K.A., Luczynski, P., Dinan, T.G. and Cryan, J.F. (2016) Reframing the Teenage Wasteland: Adolescent Microbiota-Gut-Brain Axis. The Canadian Journal of Psychiatry, 61, 214-221. https://doi.org/10.1177/0706743716635536

[67] Allais, L., Kerckhof, F.M., Verschuere, S., Bracke, K.R., De Smet, R., Laukens, D., Van den Abbeele, P., De Vos, M., Boon, N., Brusselle, G.G. and Cuvelier, C.A. (2016) Chronic Cigarette Smoke Exposure Induces Microbial and Inflammatory Shifts and Mucin Changes in the Murine Gut. Environmental Microbiology, 18, 1352-1363. https://doi.org/10.1111/1462-2920.12934

[68] Shanahan, E.R., Shah, A., Koloski, N., Walker, M.M., Talley, N.J., Morrison, M. and Holtmann, G.J. (2018) Influence of Cigarette Smoking on the Human Duodenal Mucosa-Associated Microbiota. Microbiome, 6, 150. https://doi.org/10.1186/s40168-018-0531-3

[69] Savin, Z., Kivity, S., Yonath, H. and Yehuda, S. (2018) Smoking and the Intestinal Microbiome. Archives of Microbiology, 200, 677-684. https://doi.org/10.1007/s00203-018-1506-2

[70] Lee, S., Yun, Y., Kim, S., Lee, E.J., Chang, Y., Ryu, S., Shin, H., Kim, H.L., Kim, H.N. and Lee, J. (2018) Association between Cigarette Smoking Status and Composition of Gut Microbiota: Population-Based Cross-Sectional Study. Journal of Clinical Medicine, 7, 282. https://doi.org/10.3390/jcm7090282

[71] World Health Organization (WHO) (2004) Global Status Report: Alcohol Policy. Department of Mental Health and Substance Abuse, Geneva.

[72] Lim, S.S., Vos, T., Flaxman, A.D., Danaei, G., Shibuya, K., Adair-Rohani, H., AlMazroa, M.A., Amann, M., Anderson, H.R., Andrews, K.G. and Aryee, M. (2012) A Comparative Risk Assessment of Burden of Disease and Injury Attributable to 67 Risk Factors and Risk Factor Clusters in 21 Regions, 1990-2010: A Systematic Analysis for the Global Burden of Disease Study 2010. The Lancet, 380, 2224-2260.

[73] Leclercq, S., Matamoros, S., Cani, P.D., Neyrinck, A.M., Jamar, F., Stärkel, P., Windey, K., Tremaroli, V., Bäckhed, F., Verbeke, K. and De Timary, P. (2014) Intestinal Permeability, Gut-Bacterial Dysbiosis, and Behavioral Markers of Alcohol-Dependence Severity. Proceedings of the National Academy of Sciences of the United States of America, 111, E4485-E4493. https://doi.org/10.1073/pnas.1415174111

[74] de Timary, P., Stärkel, P., Delzenne, N.M. and Leclercq, S. (2017) A Role for the Peripheral Immune System in the Development of Alcohol Use Disorders? Neuropharmacology, 122, 148-160. https://doi.org/10.1016/j.neuropharm.2017.04.013 
[75] Delzenne, N.M., Neyrinck, A.M., Bäckhed, F. and Cani, P.D. (2011) Targeting Gut Microbiota in Obesity: Effects of Prebiotics and Probiotics. Nature Reviews Endocrinology, 7, 639. https://doi.org/10.1038/nrendo.2011.126

[76] Temko, J.E., Bouhlal, S., Farokhnia, M., Lee, M.R., Cryan, J.F. and Leggio, L. (2017) The Microbiota, the Gut and the Brain in Eating and Alcohol Use Disorders: A 'Ménage à Trois'? Alcohol and Alcoholism, 52, 403-413. https://doi.org/10.1093/alcalc/agx024

[77] Brown, J.D., Naples, S.P. and Booth, F.W. (2012) Effects of Voluntary Running on Oxygen Consumption, RQ, and Energy Expenditure during Primary Prevention of Diet-Induced Obesity in C57BL/6N Mice. Journal of Applied Physiology, 113, 473-478. https://doi.org/10.1152/japplphysiol.00668.2011

[78] Bermon, S., Petriz, B., Kajeniene, A., Prestes, J., Castell, L. and Franco, O.L. (2015) The Microbiota: An Exercise Immunology Perspective. Exercise Immunology Review, 21, 70-79.

[79] Peters, H.P.F., De Vries, W.R., Vanberge-Henegouwen, G.P. and Akkermans, L.M.A. (2001) Potential Benefits and Hazards of Physical Activity and Exercise on the Gastrointestinal Tract. Gut, 48, 435-439. https://doi.org/10.1136/gut.48.3.435

[80] Matsumoto, M., Inoue, R., Tsukahara, T., Ushida, K., Chiji, H., Matsubara, N. and Hara, H. (2008) Voluntary Running Exercise Alters Microbiota Composition and Increases N-Butyrate Concentration in the Rat Cecum. Bioscience, Biotechnology, and Biochemistry, 72, 572-576. https://doi.org/10.1271/bbb.70474

[81] Evans, C.C., LePard, K.J., Kwak, J.W., Stancukas, M.C., Laskowski, S., Dougherty, J., Moulton, L., Glawe, A., Wang, Y., Leone, V. and Antonopoulos, D.A. (2014) Exercise Prevents Weight Gain and Alters the Gut Microbiota in a Mouse Model of High Fat Diet-Induced Obesity. PLoS ONE, 9, e92193. https://doi.org/10.1371/journal.pone.0092193

[82] Mika, A., Van Treuren, W., González, A., Herrera, J.J., Knight, R. and Fleshner, M. (2015) Exercise Is More Effective at Altering Gut Microbial Composition and Producing Stable Changes in Lean Mass in Juvenile versus Adult Male F344 Rats. PLoS ONE, 10, e0125889. https://doi.org/10.1371/journal.pone.0125889

[83] Taniguchi, H., Tanisawa, K., Sun, X., Kubo, T., Hoshino, Y., Hosokawa, M., Takeyama, H. and Higuchi, M. (2018) Effects of Short-Term Endurance Exercise on Gut Microbiota in Elderly Men. Physiological Reports, 6, e13935. https://doi.org/10.14814/phy2.13935

[84] Foster, J.A., Rinaman, L. and Cryan, J.F. (2017) Stress \& the Gut-Brain Axis: Regulation by the Microbiome. Neurobiology of Stress, 7, 124-136. https://doi.org/10.1016/j.ynstr.2017.03.001

[85] van de Wouw, M., Boehme, M., Lyte, J.M., Wiley, N., Strain, C., O’Sullivan, O., Clarke, G., Stanton, C., Dinan, T.G. and Cryan, J.F. (2018) Short-Chain Fatty Acids: Microbial Metabolites that Alleviate Stress-Induced Brain-Gut Axis Alterations. The Journal of Physiology, 596, 4923-4944. https://doi.org/10.1113/JP276431

[86] Kato-Kataoka, A., Nishida, K., Takada, M., Kawai, M., Kikuchi-Hayakawa, H., Suda, K., Ishikawa, H., Gondo, Y., Shimizu, K., Matsuki, T. and Kushiro, A. (2016) Fermented Milk Containing Lactobacillus casei Strain Shirota Preserves the Diversity of the Gut Microbiota and Relieves Abdominal Dysfunction in Healthy Medical Students Exposed to Academic Stress. Applied and Environmental Microbiology, 82, 3649-3658. https://doi.org/10.1128/AEM.04134-15

[87] Clark, A. and Mach, N. (2016) Exercise-Induced Stress Behavior, Gut-Microbiota-Brain Axis and Diet: A Systematic Review for Athletes. Journal of the International Socie- 
ty of Sports Nutrition, 13, 43. https://doi.org/10.1186/s12970-016-0155-6

[88] Looft, T. and Allen, H.K. (2012) Collateral Effects of Antibiotics on Mammalian Gut Microbiomes. Gut Microbes, 3, 463-467. https://doi.org/10.4161/gmic.21288

[89] Jernberg, C., Löfmark, S., Edlund, C. and Jansson, J.K. (2010) Long-Term Impacts of Antibiotic Exposure on the Human Intestinal Microbiota. Microbiology, 156, 3216-3223. https://doi.org/10.1099/mic.0.040618-0

[90] Andersson, D.I. and Hughes, D. (2011) Persistence of Antibiotic Resistance in Bacterial Populations. FEMS Microbiology Reviews, 35, 901-911. https://doi.org/10.1111/j.1574-6976.2011.00289.x

[91] Ferrer, M., Martins dos Santos, V.A., Ott, S.J. and Moya, A. (2014) Gut Microbiota Disturbance during Antibiotic Therapy: A Multi-Omic Approach. Gut Microbes, 5, 64-70. https://doi.org/10.4161/gmic.27128

[92] Maier, L., Pruteanu, M., Kuhn, M., Zeller, G., Telzerow, A., Anderson, E.E., Brochado, A.R., Fernandez, K.C., Dose, H., Mori, H. and Patil, K.R. (2018) Extensive Impact of Non-Antibiotic Drugs on Human Gut Bacteria. Nature, 555, 623-628. https://doi.org/10.1038/nature25979

[93] Laxminarayan, R. (2014) Antibiotic Effectiveness: Balancing Conservation against Innovation. Science, 345, 1299-1301. https://doi.org/10.1126/science.1254163

[94] De Filippo, C., Cavalieri, D., Di Paola, M., Ramazzotti, M., Poullet, J.B., Massart, S., Collini, S., Pieraccini, G. and Lionetti, P. (2010) Impact of Diet in Shaping Gut Microbiota Revealed by a Comparative Study in Children from Europe and Rural Africa. Proceedings of the National Academy of Sciences of the United States of America, 107, 14691-14696. https://doi.org/10.1073/pnas.1005963107

[95] Suzuki, T.A. and Worobey, M. (2014) Geographical Variation of Human Gut Microbial Composition. Biology Letters, 10, Article ID: 20131037.

https://doi.org/10.1098/rsbl.2013.1037

[96] Senghor, B., Bassène, H., Khelaifia, S., Robert, C., Fournier, P.E., Ruimy, R., Sokhna, C., Raoult, D. and Lagier, J.C. (2018) Sediminibacillus massiliensis sp. nov., a Moderately Halophilic, Gram-Positive Bacterium Isolated from a Stool Sample of a Young Senegalese Man. Antonie van Leeuwenhoek, 111, 1225-1236. https://doi.org/10.1007/s10482-018-1032-x

[97] Nicholson, J.K., Holmes, E., Kinross, J., Burcelin, R., Gibson, G., Jia, W. and Pettersson, S. (2012) Host-Gut Microbiota Metabolic Interactions. Science, 336, 1262-1267. https://doi.org/10.1126/science.1223813

[98] Rooks, M.G. and Garrett, W.S. (2016) Gut Microbiota, Metabolites and Host Immunity. Nature Reviews Immunology, 16, 341-352. https://doi.org/10.1038/nri.2016.42

[99] Louis, P., Hold, G.L. and Flint, H.J. (2014) The Gut Microbiota, Bacterial Metabolites and Colorectal Cancer. Nature Reviews Microbiology, 12, 661-672. https://doi.org/10.1038/nrmicro3344

[100] Macfarlane, G.T. and Macfarlane, S. (2011) Fermentation in the Human Large Intestine: Its Physiologic Consequences and the Potential Contribution of Prebiotics. Journal of Clinical Gastroenterology, 45, S120-S127. https://doi.org/10.1097/MCG.0b013e31822fecfe

[101] Jones, B.V., Begley, M., Hill, C., Gahan, C.G. and Marchesi, J.R. (2008) Functional and Comparative Metagenomic Analysis of Bile Salt Hydrolase Activity in the $\mathrm{Hu}$ man Gut Microbiome. Proceedings of the National Academy of Sciences of the United States of America, 105, 13580-13585. 
https://doi.org/10.1073/pnas.0804437105

[102] Swann, J.R., Want, E.J., Geier, F.M., Spagou, K., Wilson, I.D., Sidaway, J.E., Nicholson, J.K. and Holmes, E. (2011) Systemic Gut Microbial Modulation of Bile Acid Metabolism in Host Tissue Compartments. Proceedings of the National Academy of Sciences of the United States of America, 108, 4523-4530. https://doi.org/10.1073/pnas.1006734107

[103] Victor, D.W. and Quigley, E.M. (2014) Microbial Therapy in Liver Disease: Probiotics Probe the Microbiome-Gut-Liver-Brain Axis. Gastroenterology, 147, 1216-1218. https://doi.org/10.1053/j.gastro.2014.10.023

[104] Zhang, C., Zhang, M., Wang, S., Han, R., Cao, Y., Hua, W., Mao, Y., Zhang, X., Pang, X., Wei, C. and Zhao, G. (2010) Interactions between Gut Microbiota, Host Genetics and Diet Relevant to Development of Metabolic Syndromes in Mice. The ISME Journal, 4, 232. https://doi.org/10.1038/ismej.2009.112

[105] Cryan, J.F. and Dinan, T.G. (2012) Mind-Altering Microorganisms: The Impact of the Gut Microbiota on Brain and Behaviour. Nature Reviews Neuroscience, 13, 701-702. https://doi.org/10.1038/nrn3346

[106] Ragsdale, S.W. and Pierce, E. (2008) Acetogenesis and the Wood-Ljungdahl Pathway of $\mathrm{CO}_{2}$ Fixation. Biochimica et Biophysica Acta (BBA)-Proteins and Proteomics, 1784, 1873-1898. https://doi.org/10.1016/j.bbapap.2008.08.012

[107] Koh, A., De Vadder, F., Kovatcheva-Datchary, P. and Bäckhed, F. (2016) From Dietary Fiber to Host Physiology: Short-Chain Fatty Acids as Key Bacterial Metabolites. Cell, 165, 1332-1345. https://doi.org/10.1016/j.cell.2016.05.041

[108] Ruppin, H., Bar-Meir, S., Soergel, K.H., Wood, C.M. and Schmitt, M.G. (1980) Absorption of Short-Chain Fatty Acids by the Colon. Gastroenterology, 78, 1500-1507. https://doi.org/10.1016/S0016-5085(19)30508-6

[109] den Besten, G., van Eunen, K., Groen, A.K., Venema, K., Reijngoud, D.J. and Bakker, B.M. (2013) The Role of Short-Chain Fatty Acids in the Interplay between Diet, Gut Microbiota, and Host Energy Metabolism. Journal of Lipid Research, 54, 2325-2340. https://doi.org/10.1194/jlr.R036012

[110] Hijova, E. and Chmelarova, A. (2007) Short Chain Fatty Acids and Colonic Health. Bratislavské lekárske listy, 108, 354.

[111] Vogt, S.L., Pena-Diaz, J. and Finlay, B.B. (2015) Chemical Communication in the Gut: Effects of Microbiota-Generated Metabolites on Gastrointestinal Bacterial Pathogens. Anaerobe, 34, 106-115. https://doi.org/10.1016/j.anaerobe.2015.05.002

[112] Canfora, E.E., Jocken, J.W. and Blaak, E.E. (2015) Short-Chain Fatty Acids in Control of Body Weight and Insulin Sensitivity. Nature Reviews Endocrinology, 11, 577-591. https://doi.org/10.1038/nrendo.2015.128

[113] Shoaie, S., Karlsson, F., Mardinoglu, A., Nookaew, I., Bordel, S. and Nielsen, J. (2013) Understanding the Interactions between Bacteria in the Human Gut through Metabolic Modeling. Scientific Reports, 3, 2532. https://doi.org/10.1038/srep02532

[114] Hartstra, A.V., Bouter, K.E., Bäckhed, F. and Nieuwdorp, M. (2015) Insights into the Role of the Microbiome in Obesity and Type 2 Diabetes. Diabetes Care, 38, 159-165. https://doi.org/10.2337/dc14-0769

[115] Lin, H.V., Frassetto, A., Kowalik Jr., E.J., Nawrocki, A.R., Lu, M.M., Kosinski, J.R., Hubert, J.A., Szeto, D., Yao, X., Forrest, G. and Marsh, D.J. (2012) Butyrate and Propionate Protect against Diet-Induced Obesity and Regulate Gut Hormones via Free Fatty Acid Receptor 3-Independent Mechanisms. PLoS ONE, 7, e35240. https://doi.org/10.1371/journal.pone.0035240 
[116] Harris, K., Kassis, A., Major, G. and Chou, C.J. (2012) Is the Gut Microbiota a New Factor Contributing to Obesity and Its Metabolic Disorders? Journal of Obesity, 2012, Article ID: 879151. https://doi.org/10.1155/2012/782920

[117] Tremaroli, V. and Bäckhed, F. (2012) Functional Interactions between the Gut Microbiota and Host Metabolism. Nature, 489, 242-249. https://doi.org/10.1038/nature11552

[118] Wang, Z., Klipfell, E., Bennett, B.J., Koeth, R., Levison, B.S., DuGar, B., Feldstein, A.E., Britt, E.B., Fu, X., Chung, Y.M. and Wu, Y. (2011) Gut Flora Metabolism of Phosphatidylcholine Promotes Cardiovascular Disease. Nature, 472, 57-63. https://doi.org/10.1038/nature09922

[119] Elin, R.J. and Wolff, S.M. (1976) Biology of Endotoxin. Annual Review of Medicine, 27, 127-141. https://doi.org/10.1146/annurev.me.27.020176.001015

[120] Benoit, R., Rowe, S., Watkins, S.C., Boyle, P., Garrett, M., Alber, S., Wiener, J., Rowe, M.I. and Ford, H.R. (1998) Pure Endotoxin Does Not Pass across the Intestinal Epithelium in Vitro. Shock, 10, 43-48. https://doi.org/10.1097/00024382-199807000-00008

[121] Andreasen, A.S., Krabbe, K.S., Krogh-Madsen, R., Taudorf, S., Pedersen, B.K. and Moller, K. (2008) Human Endotoxemia as a Model of Systemic Inflammation. Current Medicinal Chemistry, 15, 1697-1705. https://doi.org/10.2174/092986708784872393

[122] DiBaise, J.K., Frank, D.N. and Mathur, R. (2012) Impact of the Gut Microbiota on the Development of Obesity: Current Concepts. The American Journal of Gastroenterology Supplements, 1, 22.

[123] Petsch, D. and Anspach, F.B. (2000) Endotoxin Removal from Protein Solutions. Journal of Biotechnology, 76, 97-119. https://doi.org/10.1016/S0168-1656(99)00185-6

[124] Hathaway, L.J. and Kraehenbuhl, J.P. (2000) The Role of M Cells in Mucosal Immunity. Cellular and Molecular Life Sciences CMLS, 57, 323-332. https://doi.org/10.1007/PL00000693

[125] Neal, M.D., Leaphart, C., Levy, R., Prince, J., Billiar, T.R., Watkins, S., Li, J., Cetin, S., Ford, H., Schreiber, A. and Hackam, D.J. (2006) Enterocyte TLR4 Mediates Phagocytosis and Translocation of Bacteria across the Intestinal Barrier. The Journal of Immunology, 176, 3070-3079. https://doi.org/10.4049/jimmunol.176.5.3070

[126] Cartwright, I.J., Plonné, D. and Higgins, J.A. (2000) Intracellular Events in the Assembly of Chylomicrons in Rabbit Enterocytes. Journal of Lipid Research, 41, 1728-1739.

[127] Cario, E., Rosenberg, I.M., Brandwein, S.L., Beck, P.L., Reinecker, H.C. and Podolsky, D.K. (2000) Lipopolysaccharide Activates Distinct Signaling Pathways in Intestinal Epithelial Cell Lines Expressing Toll-Like Receptors. The Journal of Immunology, 164, 966-972. https://doi.org/10.4049/jimmunol.164.2.966

[128] Cani, P.D., Possemiers, S., Van de Wiele, T., Guiot, Y., Everard, A., Rottier, O., Geurts, L., Naslain, D., Neyrinck, A., Lambert, D.M. and Muccioli, G.G. (2009) Changes in Gut Microbiota Control Inflammation in Obese Mice through a Mechanism Involving GLP-2-Driven Improvement of Gut Permeability. Gut, 58, 1091-1103. https://doi.org/10.1136/gut.2008.165886

[129] Varadharajan, K., Shanmugakonar, M., Das, S. and Al-Naemi, H. (2018) Gut microbiota Dysbiosis in Cafeteria Diet Fed Sprague Dawley Rats. Advances in Microbiology, 8, 975-993. https://doi.org/10.4236/aim.2018.812066 
[130] Alasmar, R., Varadharajan, K., Shanmugakonar, M. and Al-Naemi, H. (2019) Gut Microbiota Dysbiosis and Their Impact on biochemical and Inflammatory Profiles in cafeteria diet fed Sprague Dawley rats. Advances in Microbiology, 9, 775-789. https://doi.org/10.4236/aim.2019.99047

[131] Sandra, C.D., Hamda, A., 2017. Endothelial Nitric Oxide Activity and Bioavailability during Obesity Conditions. The UA (Undergraduate) Global Submit 2017 Companion. Qatar University, Doha, Qatar.

[132] Krych, L., Hansen, C.H., Hansen, A.K., Van Den Berg, F.W. and Nielsen, D.S. (2013) Quantitatively Different, Yet Qualitatively Alike: A Meta-Analysis of the Mouse Core Gut Microbiome with a View towards the Human Gut Microbiome. PLoS ONE, 8, e62578. https://doi.org/10.1371/journal.pone.0062578

[133] Lutz, T.A. and Woods, S.C. (2012) Overview of Animal Models of Obesity. Current Protocols in Pharmacology, 58, 5-61. https://doi.org/10.1002/0471141755.ph0561s58

[134] Arrieta, M.C., Walter, J. and Finlay, B.B. (2016) Human Microbiota-Associated Mice: A Model with Challenges. Cell Host \& Microbe, 19, 575-578. https://doi.org/10.1016/j.chom.2016.04.014

[135] Kostic, A.D., Howitt, M.R. and Garrett, W.S. (2013) Exploring Host-Microbiota Interactions in Animal Models and Humans. Genes \& Development, 27, 701-718. https://doi.org/10.1101/gad.212522.112

[136] Turner, P.V. (2018) The Role of the Gut Microbiota on Animal Model Reproducibility. Animal Models and Experimental Medicine, 1, 109-115. https://doi.org/10.1002/ame2.12022

[137] Coleman, D.L. (1978) Obese and Diabetes: Two Mutant Genes Causing Diabetes-Obesity Syndromes in Mice. Diabetologia, 14, 141-148. https://doi.org/10.1007/BF00429772

[138] Bates, S.H., Stearns, W.H., Dundon, T.A., Schubert, M., Tso, A.W., Wang, Y., Banks, A.S., Lavery, H.J., Haq, A.K., Maratos-Flier, E. and Neel, B.G. (2003) STAT3 signalling Is Required for Leptin Regulation of Energy Balance But Not Reproduction. Nature, 421, 856-859. https://doi.org/10.1038/nature01388

[139] Bray, G.A. and York, D.A. (1979) Hypothalamic and Genetic Obesity in Experimental Animals: An Autonomic and Endocrine Hypothesis. Physiological Reviews, 59, 719-809. https://doi.org/10.1152/physrev.1979.59.3.719

[140] Zierath, J.R., Ryder, J.W., Doebber, T., Woods, J., Wu, M., Ventre, J., Li, Z., McCrary, C., Berger, J., Zhang, B. and Moller, D.E. (1998) Role of Skeletal Muscle in Thiazolidinedione Insulin Sensitizer (PPAR $\gamma$ Agonist) Action. Endocrinology, 139, 5034-5041. https://doi.org/10.1210/endo.139.12.6364

[141] Ikeda, H., Shino, A., Matsuo, T., Iwatsuka, H. and Suzuoki, Z. (1981) A New Genetically Obese-Hyperglycemic Rat (Wistar Fatty). Diabetes, 30, 1045-1050. https://doi.org/10.2337/diab.30.12.1045

[142] O'Rahilly, S. (2009) Human Genetics Illuminates the Paths to Metabolic Disease. Nature, 462, 307-314. https://doi.org/10.1038/nature08532

[143] Levin, B.E. and Dunn-Meynell, A.A. (2002) Defense of Body Weight Depends on Dietary Composition and Palatability in Rats with Diet-Induced Obesity. American Journal of Physiology-Regulatory, Integrative and Comparative Physiology, 282, R46-R54. https://doi.org/10.1152/ajpregu.2002.282.1.R46

[144] Rogers, P.J. and Blundell, J.E. (1984) Meal Patterns and Food Selection during the Development of Obesity in Rats Fed a Cafeteria Diet. Neuroscience \& Biobehavioral 
Reviews, 8, 441-453. https://doi.org/10.1016/0149-7634(84)90003-4

[145] Willett, W.C. and Leibel, R.L. (2002) Dietary Fat Is Not a Major Determinant of Body Fat. The American Journal of Medicine, 113, 47-59. https://doi.org/10.1016/S0002-9343(01)00992-5

[146] Joost, H.G. (2011) The Genetic Basis of Obesity and Type 2 Diabetes: Lessons from the New Zealand Obese Mouse, a Polygenic Model of the Metabolic Syndrome. In: Meyerhof, W., Beisiegel, U. and Joost, H.G., Eds., Sensory and Metabolic Control of Energy Balance, Springer, Berlin, Heidelberg, 1-11. https://doi.org/10.1007/978-3-642-14426-4_1

[147] Becskei, C., Lutz, T.A. and Riediger, T. (2010) Reduced Fasting-Induced Activation of Hypothalamic Arcuate Neurons Is Associated with Hyperleptinemia and Increased Leptin Sensitivity in Obese Mice. American Journal of Physiology-Regulatory, Integrative and Comparative Physiology, 299, R632-R641.

https://doi.org/10.1152/ajpregu.00674.2009

[148] Faust, I.M., Johnson, P.R. and Hirsch, J. (1980) Long-Term Effects of Early Nutritional Experience on the Development of Obesity in the Rat. The Journal of Nutrition, 110, 2027-2034. https://doi.org/10.1093/jn/110.10.2027

[149] Shepherd, P.R., Gnudi, L., Tozzo, E., Yang, H., Leach, F. and Kahn, B.B. (1993) Adipose Cell Hyperplasia and Enhanced Glucose Disposal in Transgenic Mice Overexpressing GLUT4 Selectively in Adipose Tissue. Journal of Biological Chemistry, 268, 22243-22246.

[150] Davies, J.S., Gevers, E.F., Stevenson, A.E., Coschigano, K.T., El-Kasti, M.M., Bull, M.J., Elford, C., Evans, B.A., Kopchick, J.J. and Wells, T. (2007) Adiposity Profile in the Dwarf Rat: An Unusually Lean Model of Profound Growth Hormone Deficiency. American Journal of Physiology-Endocrinology and Metabolism, 292, E1483-E1494. https://doi.org/10.1152/ajpendo.00417.2006

[151] Hamda, A., Nelson, O., Lucie, C., Hamda, A.A. and Vidya, M.A. (2018) A High Carbohydrate Diet Increased Adiposity and Compromised Vasodilation in Rats. Qatar Foundation Annual Research Conference Proceedings, Qatar Foundation Annual Research Conference Proceedings, 2018, HBPD970. https://doi.org/10.5339/qfarc.2018.HBPD970

[152] Sandra, C.D. and Hamda, A.A. (2017) Animal Model for Childhood Obesity. Annual Research Forum Conference, Qatar University, Doha, Qatar.

http://hdl.handle.net/10576/5493 